\title{
Modeling and validation of a DC/DC power converter for building energy simulations: Application to BIPV systems
}

\author{
Konstantinos Spiliotis ${ }^{\mathrm{a}, \mathrm{b}, *}$, Juliana E. Gonçalves ${ }^{\mathrm{c}, \mathrm{b}}$, Wieland Van De Sande ${ }^{\mathrm{d}, \mathrm{b}}$, \\ Simon Ravyts ${ }^{\mathrm{a}, \mathrm{b}}$, Michael Daenen ${ }^{\mathrm{d}, \mathrm{b}}$, Dirk Saelens ${ }^{\mathrm{c}, \mathrm{b}}$, Kris Baert ${ }^{\mathrm{a}, \mathrm{b}}$, Johan \\ $\operatorname{Driesen}^{\mathrm{a}, \mathrm{b}}$ \\ ${ }^{a}$ ESAT-ELECTA, KU Leuven, Kasteelpark Arenberg 10 - box 2445, 3001 Leuven, Belgium \\ ${ }^{b}$ EnergyVille, Thor Park 8300, 3600 Genk, Belgium \\ ${ }^{c}$ Department of Civil Engineering - Building Physics section, KU Leuven, Kasteelpark \\ Arenberg 40, 3001 Leuven, Belgium \\ ${ }^{d}$ IMOMEC, Hasselt University, Wetenschapspark 1, 3590 Diepenbeek, Belgium
}

\begin{abstract}
European legislation on building performance and energy efficiency pushes the shift towards minimizing the environmental footprint of buildings. Buildingintegrated photovoltaics (BIPV) is a promising technology that can accelerate the transition to energy-neutral buildings. Quantifying the potential of BIPV is crucial and one means of obtaining those results is through simulation. The state-of-the-art tools offer either thermal or electrical specialization; in particular, balance of system components (BOS) such as power converters have not been studied in detail within the building simulations BIPV domain. In this paper, a multi-physics model of a BIPV integrated DC/DC converter is developed in the Modelica language, taking into account the thermal and electrical couplings inherent to power electronic systems. The model has been validated using representative outdoor BIPV measurements and a DC/DC converter prototype. It has been found that the proposed model provides reasonable accuracy and outperforms an equivalent power conditioning model in TRNSYS. To demonstrate the model's functionality, two case studies are performed. First, the temperature-dependence of the converter's efficiency and losses is quantified and analyzed and, second, the prominent contributors to the converter losses are identified and discussed.
\end{abstract}

Keywords: DC/DC converter, BIPV, building energy simulations, modeling,

${ }^{*}$ Corresponding author at: ESAT-ELECTA, KU Leuven, Kasteelpark Arenberg 10 - box 2445, 3001 Leuven, Belgium.

Email addresses: konstantinos.spiliotis@kuleuven.be (Konstantinos Spiliotis), juliana.goncalves@kuleuven.be (Juliana E. Gonçalves), wieland.vandesande@uhasselt.be (Wieland Van De Sande), simon.ravyts@kuleuven.be (Simon Ravyts),

michael.daenen@uhasselt.be (Michael Daenen), dirk.saelens@kuleuven.be (Dirk Saelens), kris.baert@kuleuven.be (Kris Baert), johan.driesen@esat.kuleuven.be (Johan Driesen) 
modelica

\section{Introduction}

\subsection{Background and motivation}

In the light of climate change, the European legislative body is taking action to reduce the environmental footprint of buildings. European regulation stipulates that all new buildings must be nearly zero energy (NZEB) as of 2021, while new public buildings should comply with the requirements already in 2018 [1. BIPV technology can help reduce the net energy consumption of buildings through environmentally friendly generation. In addition to building energy efficiency measures, BIPV may be a means of achieving energy neutrality in buildings [2], 3. At the moment, the building stock accounts for nearly $30 \%$ of the global energy demand [4].

To raise awareness around BIPV, increase market demand and help scaling the design and manufacturing of BIPV modules, it is necessary to quantify the potential benefits BIPV may bring when incorporated into building envelopes. The use of building energy simulations (BES) is a common way to quantify the energy generation, consumption, efficiency and losses in buildings [5]. Research in the domain of BES focuses in energy self-sufficient buildings, optimized energy management systems and energy storage control schemes, often incorporating PV systems into the building envelope [6, 7], 8], 9], [10. Two of the most popular BES tools are TRNSYS [11, and EnergyPlus [12. Both tools provide a set of BIPV components in their libraries and have been used for simulating BIPV systems in state of the art works [13, 14, [15, [16. In addition to the aforementioned tools, building libraries developed in Modelica are gaining ground in BES projects and studies focusing on building energy performance and heating, ventilation and air conditioning (HVAC) systems [17, [18, [19, 20], 21.

The various studies on BIPV systems performance focus either on the building physics and thermal aspects of the system or on its electrical behavior. Similarly to the works mentioned above, which focus only on building physics aspects, the studies assessing electrical architectures for BIPV systems do not consider the building envelope in great detail 22, 23. The development and simulation of power electronic models such as micro-inverters and -converters are often implemented in tools such as MATLAB-Simulink [24, [25], ANSYS [26] or Spice [27. Power converters are necessary to transform the PV power output from $\mathrm{DC}$ to $\mathrm{AC}$ or to condition it to a stable $\mathrm{DC}$ voltage level, allowing thus a safe connection to the grid. The performance of the power converter affects the total energy, efficiency, yield and performance ratio of a BIPV (sub)system. Such detailed information is important to assess the performance and life cycle of BIPV systems [28]. Consequently, the inclusion of balance of system (BOS) components in BES tools is crucial when simulating BIPV systems and benchmarking their performance. However, the state of art in BES typi- 
cally does not involve detailed models for the BOS components such as power converters.

This paper presents a validated methodology to model BOS components for BIPV systems from both the electrical and thermal perspectives in the BES domain. The Modelica-developed model is dimensioned to represent a BIPV micro-converter which transforms the output power of a curtain wall BIPV module to usable power at a constant DC voltage while it performs maximum power point tracking (MPPT) for the module. The proposed model includes a detailed estimation of the electrical power losses. Accurate loss estimation provides more representative expectations for the system performance, i.e. in terms of efficiency, power output and performance ratio among others. At the same time, it can provide important feedback to power electronic designers regarding the performance of their products under electrical loadings which represent the conditions of the built environment and the BIPV system. The proposed model is implemented within the Modelica-based openIDEAS framework [29], enabling the concurrent simulation of the thermal and electrical systems involved in building simulations. The modeling approach presented in this paper aims at minimizing the required computing time and thus allowing long-term simulations.

\subsection{Problematic}

Integrating BIPV systems into the built environment has two important consequences for the design and dimensioning of power converters. The first issue concerns the critical shading conditions typical of urban surroundings 30. Shading has been recognized as one of the main causes of energy yield reduction in PV systems [31. In addition to reducing the power production, (partial) shading events lead to the occurence of hot spots, which are associated with accelerated thermal degradation and, therefore, to lifetime and reliability issues [32.

In conventional roof installations or open-rack PV systems, shading events are either minimal or can be reduced by optimizing the relative distance between the PV modules. In BIPV applications, however, the position and inclination of the modules are determined by the building geometry and aesthetics. Because a large percentage of the potential for BIPV installation is related to façade applications [33, in which shading situations are very likely to occur, coping with shading effects is crucial for the BIPV technology to succeed [34].

To mitigate the impact of shading events, module-level micro converters are being considered as an alternative to the conventional centralized or multistring converter configurations [35, [36, 37, 38. In this way, mismatch losses between modules composing a roof or a façade due to shading conditions are avoided because each BIPV module operates at its individual maximum power point (MPP) 39]. Additional advantages of employing micro converters at the module level, such as lower installation costs and the possibility to monitor each module individually, have been discussed in 40 .

The second point is the lack of design consideration on how to facilitate the installation of BIPV modules, which has been indicated as one of the hindrances 
to the large scale of the BIPV technology [41, 42, 43, 44]. Pre-fabricated BIPV solutions can reduce the need for on-site skilled labour as well as the construction time, which improves construction efficiency and accuracy [45]. As pointed out in [4], accelerating the installation work is particularly important for cold climate regions, where the weather conditions often prevent outdoor construction work. Technical solutions that enable the plug-and-play installation concept are, hence, required.

A possible solution for both issues is the integration of (micro) converters into BIPV curtain wall elements, as shown in Figure 1. Commonly used to enclose large buildings, curtain walls are discrete panels that hang, like curtains, from the slab edges. Such wall structures are typically prefabricated lightweight, weather-tight building elements that span from floor to floor 46]. Integrating PV modules into curtain wall element is an important step toward plug-and-play systems, since such wall elements have been specifically designed to accelerate the installation work as well as to increase quality control because all the work is carried out inside a factory rather than in situ [47. The second step is then to integrate the (micro) converter into the curtain wall frame. In this way, the installation of BIPV systems from an electrical point-of-view could be simplified as well. However, because the converter performance and lifetime depends on the environmental conditions to which it is exposed [48, defining the most suitable location to place the converter inside the frame requires a more detailed analysis.

Figure 1 depicts a schematic representation of a curtain wall BIPV element as part of the building envelope. The BIPV element shown in this figure consists of a PV module integrated into the upper part of a curtain wall frame and a glazing integrated into the bottom part. A prototype of such a BIPV concept was installed in a test building in Leuven, Belgium, and its performance is currently being monitored. Additional information about the BIPV experimental setup and its performance can be found in [49. This BIPV setup will be used in this work as a reference case to investigate the conditions in which a micro-converter may operate in realistic applications.

In this paper, as indicated in Figure 1 the following six possible locations are defined: 1-TOP, 2-LATTOP (lateral top), 3-MID (middle), 4-LATBOT (lateral bottom), 5-BOT (bottom) and 6-IND (indoor). Positions 1-5 correspond to the integration of the converter within the BIPV frame, while position 6 represents the alternative in which the converter can be accomodated in the space between two floors, i.e. between the ceiling of one floor and the slab of the floor just above. The major difference between these six positions with respect to placing the converter is their temperature. Higher temperatures are expected at the positions closer to the BIPV module. The different temperature level corresponding to each position is imposed as an input on the developed converter model. The effect of varying the temperature conditions on the electrical performance of the converter is investigated.

In summary, the methodology used in this paper consists of (1) the development of a DC/DC converter model in Modelica language, (2) the validation of this model using a converter prototype tested under laboratory conditions 
that correspond to realistic operating situations, (3) the assessment of possible locations for integrating a converter within a BIPV curtain wall frame, and (4) the use of the validated model to investigate in detail the converter efficiency and losses dependence on temperature and to determine the most dominant loss factors.

The next section deals with the modeling approach; the method used for the estimation of the losses occurring at each component is presented. Section 3 describes the experimental campaign. A real boost DC/DC converter prototyped on a printed circuit board (PCB) was tested under several conditions that emulate the ones in the frame of a curtain wall BIPV module. The experimental data was used to validate the model. In order to benchmark the model developed in Modelica against a commonly used tool for BES, the results were compared to an equivalent power converter model in TRNSYS. Section 4 follows with a two-fold case study; the first part determines how the converter efficiency and losses are affected by the way it is integrated into the BIPV frame while the second part studies the prominent contributing factors to the total converter losses. Finally, the conclusions and the outlook provide a summary of the paper and present it as part of a wider effort to establish a validated coupled electrical-thermal simulation methodology for BIPV systems.

\section{Methodology}

\subsection{Modeling approach}

Modelica is a language for modeling complex and multi-domain systems. Its acausal nature makes it ideal for modeling complex physical systems without coding an overwhelming number of equations. Additionally, the solver encapsulates the mathematical knowledge and it is independent from the model itself, ensuring not only flexibility in physical modeling but also a high degree of interoperability across different working stations [50]. Modelica has several advantages for BES and has been used to that end [17, [51]. It is also considered for electrical and electronic circuit simulations [50], [52. Modelica has been used to model coupled physical systems and domains such as airflow and fast fluid dynamics in HVAC applications [53] and holistic building performance assessment [54. The high degree of flexibility and modularity are ideal for the development of BIPV system models such as PV and BOS components. In this way, a wide variety of BIPV system configurations can be considered and simulated. Considering the above, the proposed power converter model is developed in Modelica. Further to this, it can be therefore used in combination with models from openIDEAS and other Modelica-developed libraries 55.

The simulation time step in Modelica is variable and it is selected by the solver depending on events of the signal variables, such as zero crossings [56]. As a matter of fact, systems with high-frequency transient or oscillating signals are solved in very short time steps. Whilst this strategy contributes to improved accuracy, it may be consuming in terms of computational resources such as memory and time. BES tools are mostly used for long-term simulations, ranging from several months to years, especially when the system in question is being 


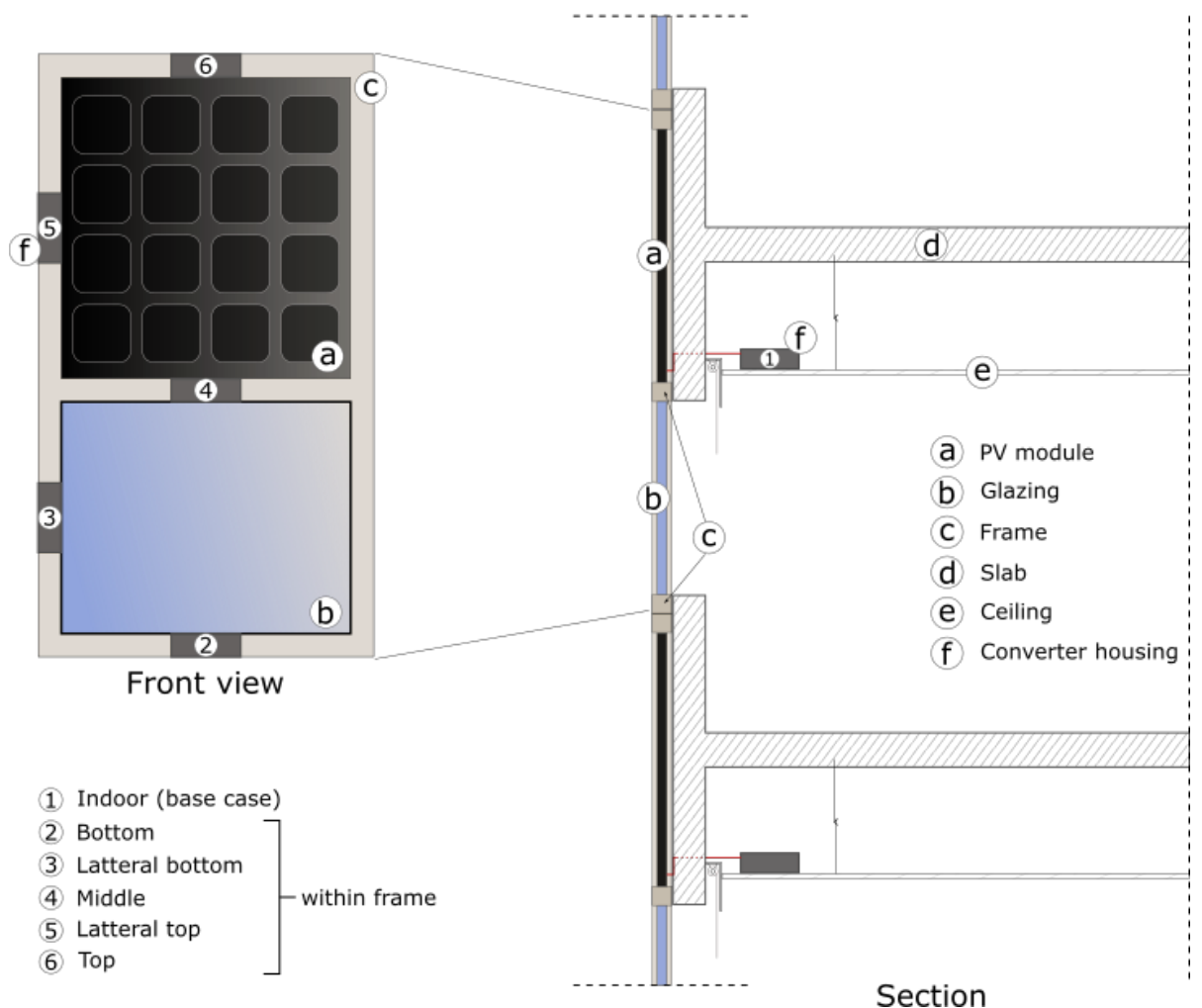

Figure 1: Schematic showing the considered BIPV curtain wall module and the different options for placing the micro-converter. As a reference the converter is placed indoors within the false ceiling (option 1), while options 2-6 seen on the curtain wall front view consider the converter placed within the frame.

dimensioned or designed. Several components within a power converter create oscillating signals which contain many zero-crossings, i.e. contain many events. As a result, the simulation time step would be rather short and a yearly simulation would require a lot of time and processing power. For example, assuming the micro-converter switching frequency is $f_{s}=100 \mathrm{kHz}$, then the simulation time step would be at maximum $T_{\text {sim }}=\frac{1}{2 \cdot f_{s}}=5 \mu \mathrm{s}$ and therefore more than 6 trillion steps to perform a year-long simulation. To tackle this problem, the average switching model is used in simulations where high-frequency dynamics do not need to be considered [57. However, the average switching converter model still includes the passive components, namely the inductor and the capacitor. Such components impose oscillations at the resonance frequency. Assuming an inductance of $L=100 \mu \mathrm{H}$ and the capacitance $C=37 \mu \mathrm{F}$, the required simula- 
tion step can be at maximum $T_{\text {sim }}=4 \pi \sqrt{L C}=764 \mu \mathrm{s}$, resulting in 40 billion steps for a 1-year simulation. As BES often require long-term simulations, such simulation steps would make this endeavor computationally costly. Therefore, the approach followed in this paper aims at eliminating all those components which impose fast-paced dynamics like switching and resonance. However, this decision creates the need for estimating the converter losses in an implicit way. Figure 2 presents conceptually the proposed converter model with its inputs, outputs and internal estimations. The methods employed for the losses and temperature estimation are discussed in the following subsections.

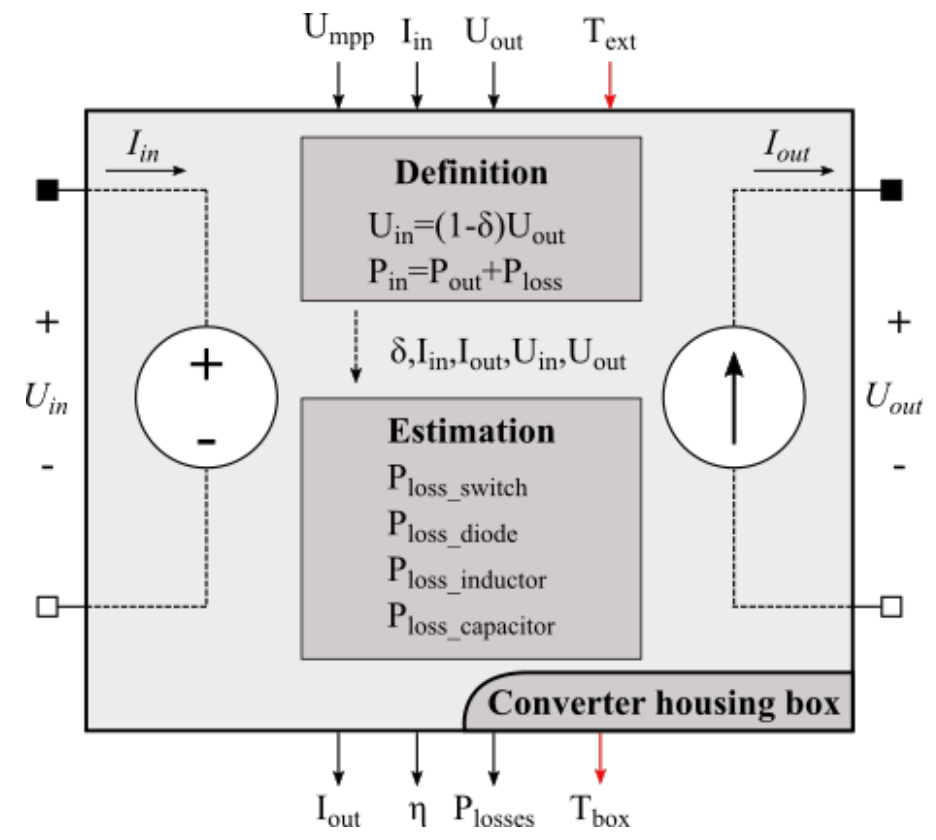

Figure 2: Representation of the proposed modeling approach. The converter maintains the input voltage at MPP $U_{i n}=U_{m p p}$ and the output voltage $U_{\text {out }}$ is assumed to be controlled. The equation-based estimations of the duty cycle and the losses are described in 2.3.

\subsection{Boost $D C / D C$ converter}

A boost DC/DC converter is a power electronics device that converts a given input voltage $U_{\text {in }}$ to a higher output voltage $U_{\text {out }}$ according to the following transfer function assuming a continuous conduction mode [58]:

$$
\frac{U_{\text {out }}}{U_{\text {in }}}=\frac{1}{1-\delta}
$$

The electrical topology of this converter is shown in Fig. A.10 in the appendix and consists of an inductor $\mathrm{L}$, a switch $\mathrm{S}$, a diode $\mathrm{D}$, a capacitor $\mathrm{C}$ and a resistor $\mathrm{R}$, which represents the load. The behavior of the converter is based on 
periodically opening and closing the switch, according to a duty ratio $\delta$, defined as:

$$
\delta=\frac{t_{\text {on }}}{T_{s}}
$$

where $t_{o n}$ is defined as the on time and $T_{s}$ as the switching period, which is the inverse of the switching frequency $f_{s}$. During the on time, $\mathrm{S}$ is closed and energy is stored in the inductor. During the off time this energy is transferred via the diode to the output capacitor $\mathrm{C}$.

Boost converters are frequently used in PV applications for a variety of power levels [59], 60, 61, 62. The input terminals are connected to the PV module and the output terminal can be directly connected to a load or to a second conversion stage if, for example, an $\mathrm{AC}$ voltage is required at the output. Boost converters have a continuous input current, which is beneficial to interface with the PV panel as the required input capacitance decreases and the MPP can be tracked more accurately. Furthermore, the converters operation principle allows to simultaneously track the MPP and increase the output voltage level, which is beneficial to reduce the required copper $(\mathrm{Cu})$ cross section at the output due to the lower current stresses.

\subsection{Power losses estimation}

The typical boost DC/DC converter topology of Fig. A.10 is assumed in order to derive the equations of the currents flowing through the assumed components. Such a topology is explained in detail in the chapters $7-4$ in 58 . The model developed in this paper estimates switching and conduction losses in the switch and the diode, inductor losses due to $\mathrm{DC}$ and $\mathrm{AC}$ resistance as well as core losses and, finally, equivalent series resistance (ESR) losses in the output capacitor. The same kind of losses are considered also in 63. The objective is to provide a loss model which is not only current- but also temperaturedependent. As such, the converter model can be used to determine the thermal effect of the placement of the converter. For example, what would be the impact on efficiency and losses when integrating the converter within the curtain wall frame?

The developed model adopts the method presented in 64 in order to estimate the switching and conduction losses at the switch. This method allows the estimation of the switch losses by using the information given in the specification sheet and the current operating conditions of the converter, i.e. the electrical loading and the surrounding temperature. The former are represented as input parameters, while the latter are inputs from other simulation blocks such as a PV module, a BIPV frame and a DC grid. The losses at the switch consist of switching and conduction losses and are estimated according to Eq3 and Eq 4 , respectively. The on and off switching times, $t_{o n}$ and $t_{o f f}$, are estimated as a function of the gate-drain capacitance of the MOSFET, $C_{G D}$, and the drain-source resistance, $R_{D S, \text { on }}$, which is temperature-dependent. The proposed model uses look-up tables to determine the $C_{G D}$, the specification sheet provides the $C=f\left(U_{D S}\right)$ diagram. The temperature dependence of $R_{D S \text {, on }}$ 
is implemented by a polynomial curve fitting to the $R_{D S, \text { on }}=f\left(T_{j}\right)$ diagram, which is also provided in the specifications of the semiconductor.

$$
\begin{gathered}
P_{S, S w}=\frac{U_{\text {out }} \cdot I_{S, \text { on }} \cdot t_{\text {on }} \cdot f_{s}}{2}+\frac{U_{\text {out }} \cdot I_{S, \text { off }} \cdot t_{\text {off }} \cdot f_{s}}{2}+Q_{r r} \cdot U_{\text {out }} \cdot f_{s} \\
P_{S, \text { Cond }}=R_{D S, \text { on }} \cdot I_{S, \text { rms }}^{2}
\end{gathered}
$$

The diode switching and conduction losses are determined according to the approach described in 64. Similarly to the losses at the switch, they also consist of conduction and the switching losses. The estimation of diode losses is performed according to Eq 5 and $\mathrm{Eq} 6$. The diode conduction losses are temperature-dependent through the forward resistance, $R_{F}$, and the diode switching losses, through the reverse recovery charge, $Q_{r r}$.

$$
\begin{gathered}
P_{D, \text { Cond }}=U_{F} \cdot I_{D, \text { avg }}+R_{F} \cdot I_{D, r m s} \\
P_{D, S w}=\frac{Q_{r r} \cdot U_{o u t} \cdot f_{s}}{4}
\end{gathered}
$$

Apart from the switching cell, the model also considers the losses in the passive components. The inductor losses consist of the losses due to the DC resistance, $R_{D C}$, the losses due to the $\mathrm{AC}$ resistance, $R_{A C}$, and finally the core losses, which are determined according to Eq,7, Eq,8 and Eq.9, respectively. $P_{L, D C R}$ and $P_{L, A C R}$ are temperature-dependent. The temperature dependence of the $R_{D C}$ is implemented through a polynomial curve fitting from its specifications. $R_{A C}$ is dependent on $R_{D C}$ and is estimated according to the Dowell's equation [65].

$$
\begin{gathered}
P_{L, D C R}=R_{D C} \cdot I_{L}^{2} \\
P_{L, A C R}=R_{A C} \cdot \frac{\Delta I_{L}^{2}}{3} \\
P_{L, \text { core }}=\frac{f_{s}}{\frac{4 \cdot 10^{9}}{B_{p}^{3}}+\frac{3 \cdot 10^{8}}{B_{p}^{2,3}}+\frac{2,7 \cdot 10^{6}}{B_{p}^{1,65}}}+8 \cdot f_{s}^{2} \cdot B_{p}^{2} \cdot 10^{-15}
\end{gathered}
$$

Finally, the output capacitor losses are estimated according to Eq10, The definition of the equivalent series resistance (ESR) losses depends on the duty cycle, $\delta$, the capacitance and the switching frequency.

$$
P_{C}=R_{E S R} \cdot I_{C, r m s}^{2}
$$




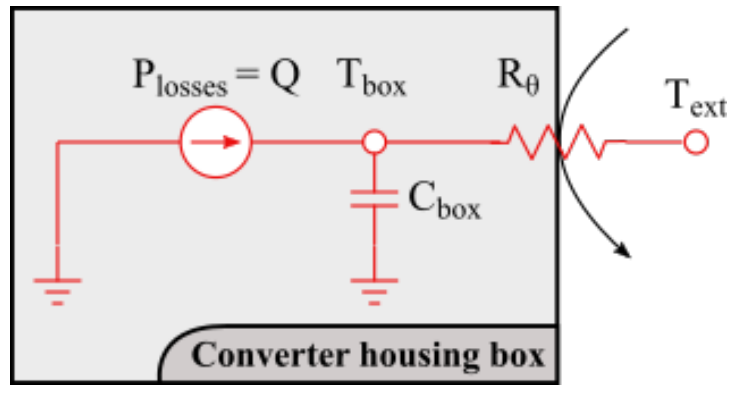

Figure 3: Representation of the thermal model of the converter using a Cauer type equivalent thermal circuit, where the heat flux $Q$ is assumed to be equal to the electrical losses of the converter.

\subsection{Operating temperature estimation}

The operating temperature of the converter is a crucial parameter. Higher operating temperature has a negative effect on the efficiency and, very importantly, it accelerates the components degradation. To account for these thermal effects, the developed model provides the possibility to estimate the operating temperature of the converter given the temperature on its exterior and the operating point.

The use of equivalent thermal-electrical circuits is common for the purposes of determining or optimizing system parameters [66]. A Cauer-type equivalent thermal circuit has been modeled and dimensioned to replicate the tested converter. The circuit is illustrated in Fig 3 The power losses in the converter components are estimated according to section 2.3 and are injected as heat flux into the thermal circuit via a heat source. A similar approach is followed in [67, where the electrical mission profile is fed to a wind-turbine inverter and the estimated electrical losses are given as input to the thermal model for component lifetime estimation. The converter box has a heat capacitance which is estimated by assuming the density of dry air and the volume of the actual converter housing box under test. The external temperature, $T_{\text {ext }}$, is known, and the thermal resistance, $R_{\theta}$, of the heat transfer is estimated according to Eq.11. where $h_{c}$ is the convective heat transfer coefficient (CHTC) and $A$ is the surface area of the converter housing box.

$$
\begin{gathered}
R_{\theta}=\frac{1}{h_{c} \cdot A} \\
\frac{\mathrm{d} Q}{\mathrm{~d} t}=\frac{1}{R_{\theta}} \cdot \Delta T=\frac{1}{R_{\theta}} \cdot\left(T_{b o x}-T_{e x t}\right)
\end{gathered}
$$

For indoor surfaces subject to free convection, a representative value for the CHTC is $3 \mathrm{~W} / \mathrm{m}^{2} \cdot K[68$. However, a wider range of CHTC values were tested and the value which minimizes the relative error between the estimated and the measured $T_{b o x}$ is selected. The thermal model described above does not consider the convective heat transfer between each component and the air 
inside the box, neither the conductive and radiative parts of the heat transfer among the thermal masses. To compensate for those simplifications, a higher value for CHTC might be more suitable. A detailed presentation of the results is presented on Table 1, where a range of equivalent heat transfer values from 3 to $15 \mathrm{~W} / \mathrm{m}^{2} \cdot K$ is tested. The six positions described in this table are indicated in 1 .

The temperature inside the converter housing box, $T_{b o x}$, is the converter operating temperature and it is assumed that all components are in thermal steady state. The temperature $T_{b o x}$ is estimated according to Eq.12, The convergence to this temperature is achieved through iterating the estimation of the losses which are temperature-dependent and of the temperature which is losses-dependent since $Q_{b o x \rightarrow e x t}=P_{\text {losses }}$.

\begin{tabular}{ccccccc}
\hline CHTC $\left(W / m^{2} \cdot K\right)$ & \multicolumn{5}{c}{ MRE $(\%)$} \\
\hline Position & 1-IND & 2-BOT & 3-LATBOT & 4-MID & 5-LATTOP & 6 -TOP \\
\hline 3 & $\mathbf{1 1 . 0 4}$ & $\mathbf{4 . 3 3}$ & 5.04 & 6.56 & 7.13 & 6.67 \\
4 & 12.15 & 4.55 & $\mathbf{4 . 9 2}$ & 6.29 & 6.99 & 6.43 \\
5 & 12.81 & 5.11 & 5.43 & $\mathbf{6 . 2 3}$ & $\mathbf{6 . 9 8}$ & $\mathbf{6 . 3 8}$ \\
6 & 13.27 & 5.49 & 5.75 & 6.27 & 7.01 & 6.40 \\
7 & 13.58 & 5.77 & 5.98 & 6.37 & 7.06 & 6.41 \\
8 & 13.83 & 5.98 & 6.19 & 6.50 & 7.12 & 6.45 \\
9 & 13.99 & 6.11 & 6.34 & 6.65 & 7.14 & 6.49 \\
10 & 14.16 & 6.29 & 6.46 & 6.73 & 7.18 & 6.51 \\
11 & 14.28 & 6.39 & 6.54 & 6.81 & 7.25 & 6.55 \\
12 & 14.37 & 6.45 & 6.62 & 6.91 & 7.28 & 6.58 \\
13 & 14.46 & 6.56 & 6.70 & 6.93 & 7.32 & 6.60 \\
14 & 14.53 & 6.59 & 6.75 & 6.99 & 7.38 & 6.62 \\
15 & 14.58 & 6.62 & 6.80 & 7.05 & 7.41 & 6.63 \\
\hline
\end{tabular}

Table 1: Sensitivity analysis of the CHCT on the relative error between the estimated and the measured $T_{b o x}$ for all the possible placements for the converter. The minimal relative error values per position are indicated in bold.

\section{Experimental validation and benchmarking}

\subsection{Description of the validation experiment}

The modeling methodology presented in the previous section is investigated through a validation experiment. The purpose of this experiment is to compare the model estimated outputs to the experimentally measured values. In this way, the accuracy of the developed models can be quantified, since the same boundary conditions are imposed on the experimental setup and on the model. Fig. 4 shows the work flow for validating the proposed micro-converter model. The boundary conditions for the validation have been obtained from the outdoor BIPV test facility in Leuven while the temperature gradient within the BIPV frame is estimated with the finite element method. A climate chamber replicates the frame temperature. The use of a climate chamber is adopted in a number 


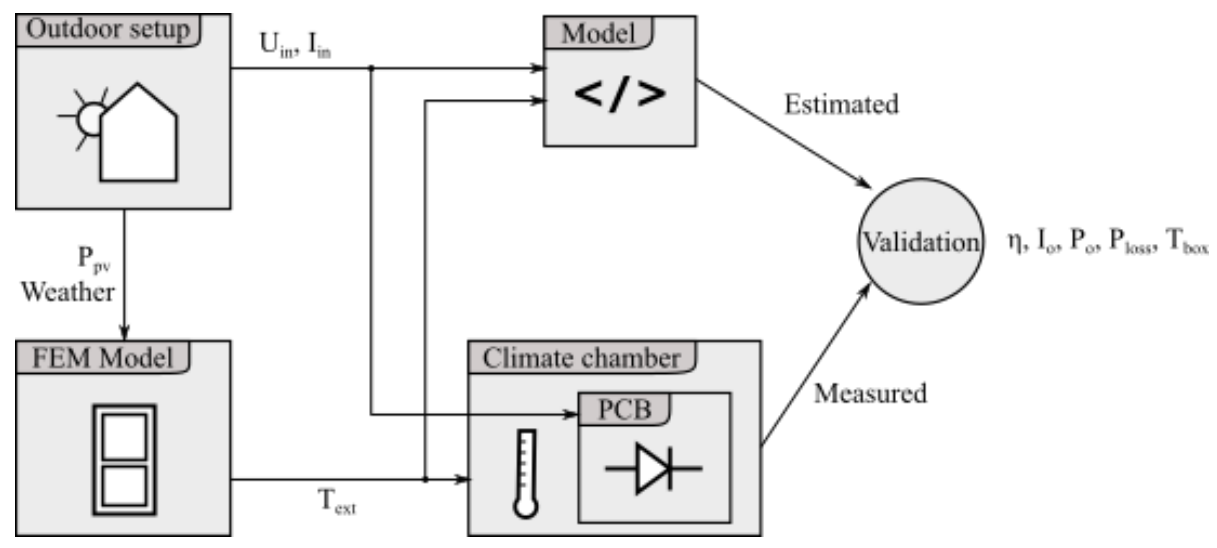

Figure 4: Work flow of the procedure followed to experimentally validate the proposed model.

of studies that focus on the validation of physical models [69, [70]. Finally, the model-estimated values of selected performance parameters has been compared to the experimentally measured ones.

A boost DC/DC converter prototyped on a PCB has been used and its parameters were used to parametrize the model. Details about the converter topology and the parameters can be found in [71. It should be noted that the prototype is an interleaved boost converter consisting of 3 legs, however for the purposes of this work we operated only one leg and therefore the resulting circuit corresponds to the generic DC/DC converter model depicted on Figure A.10. The converter was placed in a custom-made box made of plexiglass. The surface temperatures of each of the converter components, the air temperature inside the box and the ambient temperature are measured using K-type thermocouples. A thermal camera was used as an additional means of verification of the acquired temperature measurements. For the photovoltaic generation, which is the input to the converter, meteorological and electrical measurements were used from a BIPV outdoor test facility in Leuven, Belgium 49.

The temperature surrounding the converter, i.e. the temperature inside the BIPV frame, is given as an input. Simulations have shown that the converter temperature, $T_{b o x}$, is influenced by its surrounding temperature, $T_{e x t}$, but not the other way around. Figure A.13 shows that allowing a bi-direction heat transfer between the converter and the BIPV will not influence $T_{\text {ext }}$ and therefore it can be safely considered a boundary condition. For the validation and the case study, we assume six different placing options for the converter as explained previously and shown in Figure 1.

To estimate the air temperature within the frame (i.e. the positions 1-5), the Finite Element Method (FEM) was employed to model the BIPV curtain wall element; an approach likewise adopted in [72. Given the weather conditions and the power produced by the BIPV module, the model can provide 


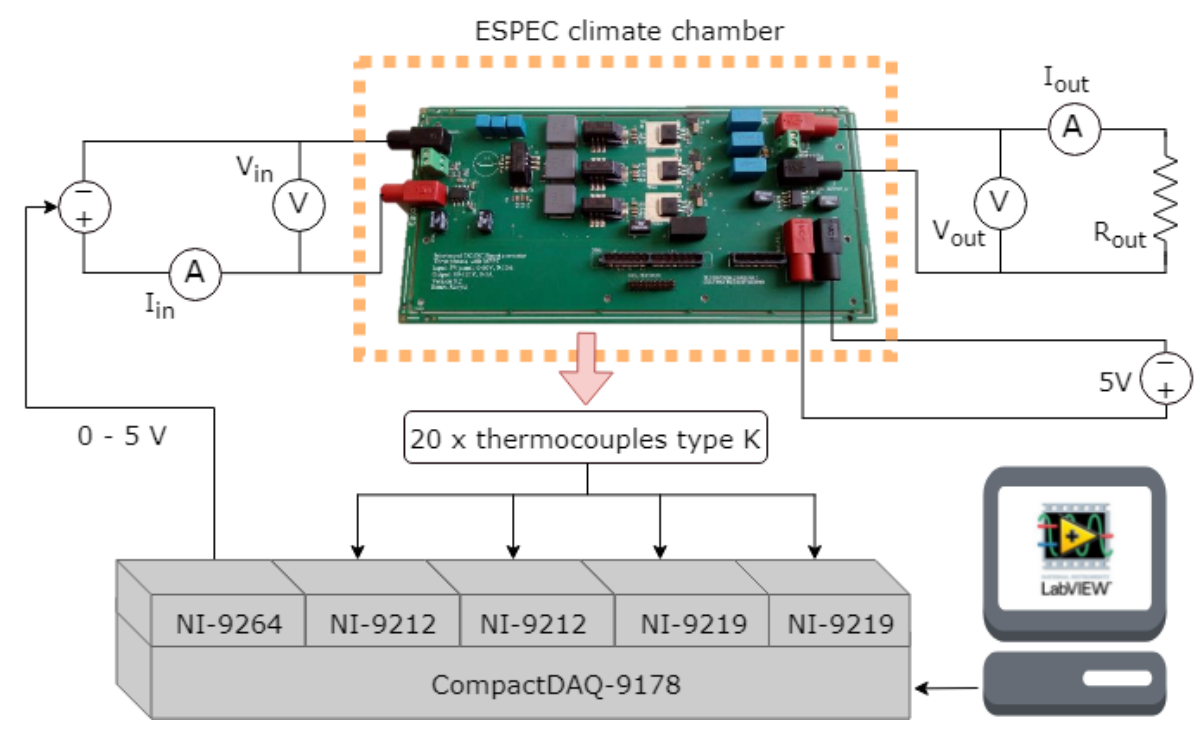

Figure 5: Metrological setup for the thermal characterization of DC/DC converters.

the temperature at any location within the structure and, therefore, can provide the information needed to define suitable locations to place the converter. The model has been validated using measurements from the BIPV curtain wall setup [49]. The analysis presented in [49] focuses on a worst-case scenario, where high solar irradiation and high ambient temperature occur simultaneously. In this paper, investigating high temperature conditions in a worse-case cenario is also interesting, since the converter performance decreases as its temperature increases. In such conditions, the PV module experienced temperatures near $80^{\circ} \mathrm{C}$, defining a very critical situation for the electronic components integrated into the BIPV structure concerning also reliability aspects. Finally, for position 6-IND, a stable temperature of $22^{\circ} \mathrm{C}$ has been assumed.

For each of the aforementioned options for placing the converter within the BIPV module frame, we compare the converter losses, output power and current estimations using the proposed model with the corresponding experimental measurements. Since the proposed models are intended for building energy simulations (BES), the model's accuracy is benchmarked also against the accuracy obtained using a power conditioner model available in TRNSYS, since it is one of the most popular BES tools. The different building blocks of this experiment are discussed in detail in the following subsections.

\subsection{Metrology}

The setup shown in Fig. 5 was designed in order to validate the proposed electro-thermal model. It is capable of emulating various different converter 
mission profiles which consist of power and ambient temperature while simultaneously logging 20 different temperatures inside the converter's case. The experimental procedure consists of four main steps, which are explained in detail next.

First, a power profile is imported into LabVIEW consisting of input voltage, $U_{i n}$, and input current, $I_{i n}$. These points are determined based on the output resistance, $R_{\text {out }}$, and the converter's duty cycle, $\delta$, as seen in Eq. 13 . $R_{\text {out }}$ and $\delta$ were given a respective value of $23.6 \Omega$ and $30 \%$ in order to keep $V_{i n}$ and $I_{\text {in }}$ within the converter component's operating limits at the maximum input power of $100 \mathrm{~W}$ per stage. The acquired voltage and current profiles are then translated into two $0 \mathrm{~V}$ to $5 \mathrm{~V}$ analogue output signals for the NI-9264 which serve as an input for the Delta power supply.

$$
U_{\text {in }}=(1-\delta) \cdot \sqrt{P \cdot R_{\text {out }}}
$$

Second, the ambient temperature profile is programmed into the ESPEC climate chamber. Due to relatively slow temperature variations and the constraint of manual programming, a slower sample time can be used combined with the climate chamber's ramp control. The option for humidity control is not enabled as the converter is encased in a custom waterproof box.

Third, type K thermocouples and Tektronix DMM4050 multimeters are used for the thermal and electrical measurements. This type of thermocouples is widely used due to its low cost and broad temperature range of $-220^{\circ} \mathrm{C}$ to $1350^{\circ} \mathrm{C}$. In 73 , the total uncertainty was estimated as $\pm 1 \%$ of the reading in absolute temperature below $400 \mathrm{~K}$. The thermal data is logged into LabVIEW using the CompactDAQ's NI-9212 and NI-9219 input cards. The multimeters have an accuracy of up to $0.0024 \% U_{d c}$ and are connected to the PC with USB to RS-232 interface adapter cables.

Lastly, the DC/DC converter's Texas Instruments microcontroller is powered by an auxiliary $5 \mathrm{~V}$ power source. This controller sets the duty cycle, $\delta$, to the previously determined $30 \%$.

\subsection{Benchmark model in TRNSYS}

In addition to the experimental validation, the proposed model developed in Modelica and described in sections 2.2 and 2.3 is benchmarked against the power conditioning model available in TRNSYS. Since the developed model is intended for use in building energy simulations, a benchmark with TRNSYS provides a relevant comparison in addition to the measurements obtained through the experiment described in 3.1 and 3.2. A power conditioner model is available in TRNSYS library as Type 175 [74. Its mathematical model is based on empirical efficiency curves for power electronic units such as DC/DC converters. Both in the proposed model in Modelica and in TRNSYS, the converter parameters are set to match the one from the experiment. The values of those parameters needed to define the power conditioning unit in TRNSYS are given in Table 2. For the purposes of this benchmark, the same input has been used in the developed model in Modelica, in the experimental setup and finally on the TRNSYS simulation studio configuration seen on Figure A.11. 


\begin{tabular}{lc}
\hline Parameter & Value \\
\hline Nominal power & $110 \mathrm{~W}$ \\
Idling constant & 0 \\
Ohmic constant & $21.25 \mathrm{~V}^{2}$ \\
Number of parallel units & 1 \\
Parasitic power & $0 \mathrm{~W}$ \\
\hline
\end{tabular}

Table 2: Parameters used for the Type 175 model configuration. The parameters have been adjusted to match those of the converter modeled in Modelica and the actual converter used for the experimental validation.

\subsection{Results}

Experimental measurements have been used in order to quantify the proposed model's accuracy. The same conditions have been used as input both to the proposed model in Modelica, but also to the equivalent model in TRNSYS for benchmarking purposes since TRNSYS is one of the most widely used BES tool. The selected key performance indicators (KPI) to perform the validation comprise of converter efficiency $\eta$, output current $I_{o}$ and power $P_{o}$, losses $P_{\text {loss }}$ and the air temperature inside converter's casing $T_{b o x}$.

Figure 6 shows the average mean relative error (MRE) rates averaged across the different placement scenarios. Table 3 provides a more detailed view on the MRE rates per KPI in each of the different converter placement scenarios. These results indicate that the proposed model outperforms the equivalent model in TRNSYS in all the studied cases by providing a smaller MRE compared to the experimental measurements.

\begin{tabular}{ccccccc}
\hline KPI & \multicolumn{7}{c}{ MRE (\%) (Modelica/TRNSYS) } \\
\hline & 1-IND & 2-BOT & 3-LATBOT & 4-MID & 5-LATTOP & 6-TOP \\
\hline$\eta$ & $\mathbf{4 . 4} / 5.8$ & $\mathbf{4 . 4} / 6.0$ & $\mathbf{4 . 5} / 5.7$ & $\mathbf{4 . 4} / 5.9$ & $\mathbf{4 . 4} / 5.4$ & $\mathbf{4 . 4} / 5.9$ \\
$I_{o}$ & $\mathbf{2 . 6} / 5.9$ & $\mathbf{2 . 6} / 6.0$ & $\mathbf{2 . 6} / 5.8$ & $\mathbf{2 . 8} / 6.1$ & $\mathbf{2 . 8} 66.5$ & $\mathbf{3 . 7} / 5.9$ \\
$P_{o}$ & $4.5 / 6.3$ & $\mathbf{4 . 4} / 6.3$ & $\mathbf{4 . 5} / 6.2$ & $\mathbf{4 . 4} / 6.3$ & $\mathbf{4 . 4} / 9.6$ & $\mathbf{4 . 4} / 6.2$ \\
$P_{\text {loss }}$ & $\mathbf{1 3 . 2} / 35.4$ & $\mathbf{1 2 . 5} / 37.9$ & $\mathbf{1 3 . 5} / 32.3$ & $\mathbf{1 2 . 6} / 38.1$ & $\mathbf{1 3 . 1} / 31.4$ & $\mathbf{1 2 . 5} / 37.5$ \\
$T_{\text {box }}$ & $\mathbf{1 1 . 0} /-$ & $\mathbf{4 . 3} /-$ & $\mathbf{4 . 9} /-$ & $\mathbf{6 . 2} /-$ & $\mathbf{7 . 0} /-$ & $\mathbf{6 . 4} /-$ \\
\hline
\end{tabular}

Table 3: Sensitivity analysis of the CHCT on the relative error between the estimated and the measured $T_{b o x}$ for all the possible placements for the converter. The minimal relative error values per position are indicated in bold.

As shown in Figure 6 and Table 3 , the MRE stays below the threshold of $5 \%$ regarding efficiency, output current and power estimations. At the same time, the corresponding MRE values using the TRNSYS model are approximately $6 \%$. The estimation of those KPI performed with the proposed model can reduce the MRE by approximately $25 \%$ compared to TRNSYS. When it comes to losses, the MRE reduction is more important. While the TRNSYS model estimates the losses with MRE between $31 \%$ and $38 \%$ compared to the measured values, the 


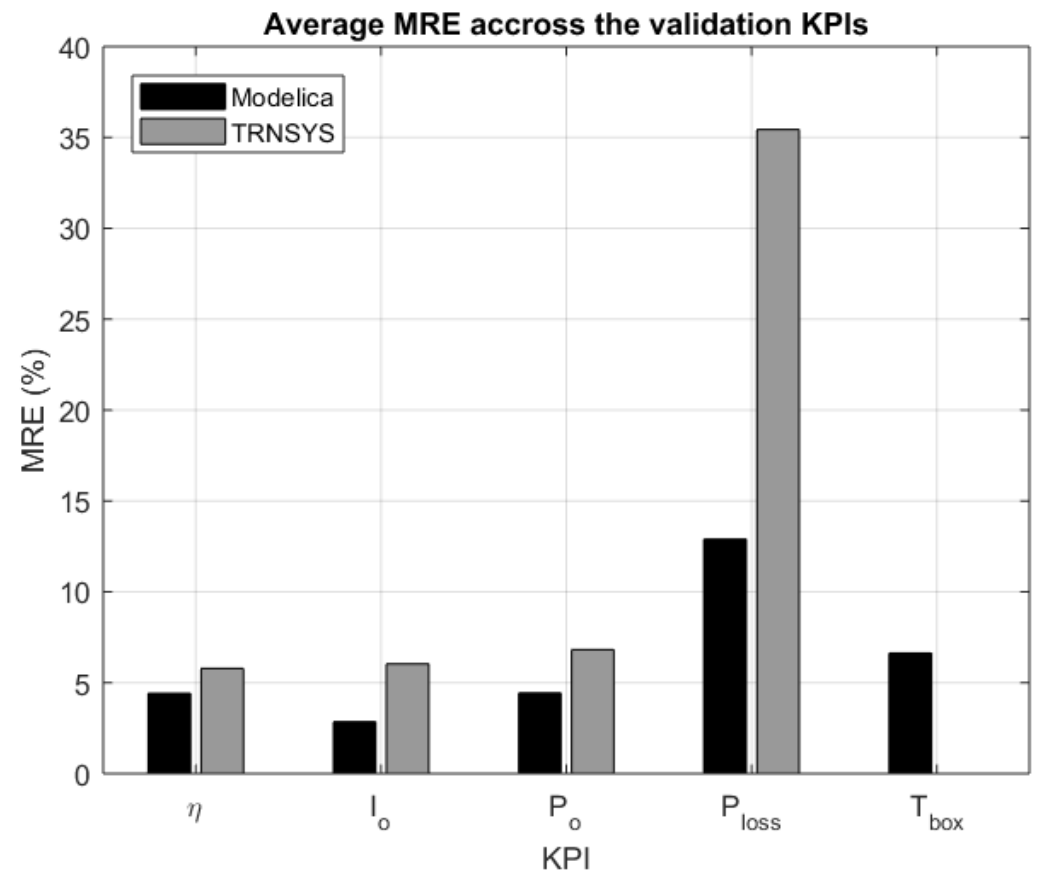

Figure 6: MRE values for each of the KPI averaged across the different placement scenarios. The model available in TRNSYS does not have a temperature estimation functionality and therefore only the MRE for the proposed model is shown.

proposed model performs the same calculations with MRE fluctuating around $13 \%$. Finally, the proposed model estimates the air temperature within the converter with MRE from $4.3 \%$ to $11 \%$ in the different scenarios. Apart from the indoor scenario, this error reaches up to a maximum of $7 \%$. However, when the ambient temperature is low, a control chipset attached to the experimental converter generates substantial heat that results in increased MRE since this control card is not modeled. Figure A.18 shows that the measurement always exceeds the estimation in the indoor scenario, which corroborates this theory.

The validation experiment has shown that the proposed model can estimate the micro-converter efficiency, output current and power, losses and box temperature with average errors of $4.4 \%, 2.9 \%, 4.4 \%, 13.1 \%$ and $6.6 \%$, respectively. Furthermore, the benchmarking against an equivalent converter model developed in TRNSYS has shown that the proposed model outperforms the one in TRNSYS in each of the KPI. The power conditioner model in TRNSYS performs power losses and efficiency estimations with the use of generic empirical curves, not considering the specific components of the converter. Additionally, the TRNSYS model does not have the functionality for the converter temperature estimation. The proposed model can be therefore used to simulate BIPV 
systems in the context of BES, since it can further reduce the estimation error demonstrated by TRNSYS, a leading BES tool.

\section{Case study}

Further to its validation, the proposed micro-converter model developed in Modelica is used in a case study. The purpose of this case study is two-fold. First, the relationship between the micro-converter's losses and efficiency and the temperature under which it performs is investigated. As a result of this analysis, losses and efficiency temperature-dependence coefficients are derived. Second, the distribution of losses among the converter's components is studied, as well as how it evolves under different temperature conditions.

Same as before, the input data for this case study consists of the PV power generation on 29 August 2017. The same scenarios from "1-IND" to "6-TOP" are considered providing therefore the different temperature profiles for this study.

\subsection{Temperature-dependence of converter losses and efficiency}

The first part of this case study focuses on the dependence between temperature and the converter efficiency and losses. Such a study may provide a guideline regarding the design of a BIPV system. For reasons such as improving system compactness and creating a scalable product, the idea of producing 'plug-and-play' BIPV modules has been contemplated. An integrated microconverter unit will be used to stabilize the output voltage of the BIPV module allowing the connection to a DC grid, while constantly tracking its MPP. In a so called 'plug-and-play' BIPV module, the converter may be placed within its frame. However, the temperature around the micro-converter will be higher compared to the ambient conditions or indoors an acclimatized space. Besides, the temperature dependence of the power losses and the efficiency, higher temperatures have negative impact on the lifetime and reliability of power electronic devices [75], [76]. The scenarios considered are depicted in Figure 1 and consist of 5 different positions in the frame, in the top, bottom, middle and lateral sides of it, as well as indoors as a base case.

Figures 7 and 8 show the sensitivity of the efficiency and power losses to converter placement. As shown, these dependences are limited to coefficients of magnitudes in the power of minus four. The precise values of those coefficients are given in Table 4. The results of this case study suggest that efficiency and power losses would not face a significant impact if the micro-converter is integrated within the frame and therefore surrounded by higher temperatures. The measured MRE values suggest that such correlation might be insignificant and largely affected by estimation errors. However, both coefficients follow the expected trends, i.e. positive correlation between power losses and temperature, and negative correlation between efficiency and temperature. That observation might indicate that a large contributor to MRE is systematic errors.

Figure 9 depicts three temperature-related KPI and how they vary in the different scenarios for converter placement. The evolution of average and spread 


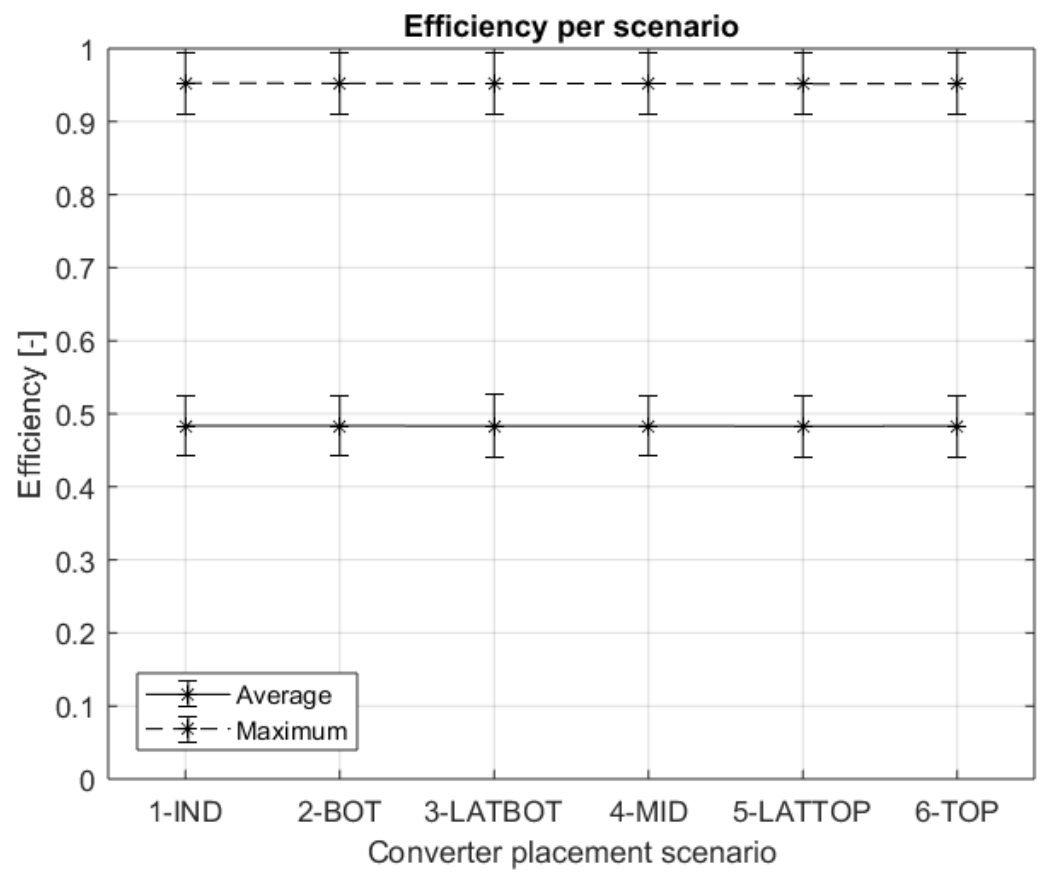

Figure 7: Average and maximal values of the converter efficiency estimated for each of the placement scenarios.

\begin{tabular}{cccccccc}
\hline & \multicolumn{7}{c}{ Average values } \\
KPI & 1-IND & 2-BOT & 3-LATBOT & 4-MID & 5-LATTOP & 6-TOP & T-coefficient \\
\hline Temperature $\left[{ }^{\circ} \mathrm{C}\right]$ & 23.2 & 28.2 & 29.7 & 32.9 & 32.2 & 35.3 & \\
\hline Efficiency $[-]$ & 0.4835 & 0.4836 & 0.4834 & 0.4835 & 0.4830 & 0.4834 & $-2.89 \mathrm{e}-041 /{ }^{\circ} \mathrm{C}$ \\
Losses $[\mathrm{W}]$ & 0.4737 & 0.4776 & 0.4769 & 0.4806 & 0.4802 & 0.4811 & $+5.79 \mathrm{e}-04 \mathrm{~W} /{ }^{\circ} \mathrm{C}$ \\
& \multicolumn{7}{c}{ Maximum values } \\
KPI & 1-IND & 2-BOT & 3-LATBOT & 4-MID & 5-LATTOP & 6 -TOP & T-coefficient \\
\hline Temperature $\left[{ }^{\circ} \mathrm{C}\right]$ & 26.2 & 37.9 & 45.9 & 63.4 & 73.4 & 75.1 & \\
\hline Efficiency $[-]$ & 0.9526 & 0.9525 & 0.9522 & 0.9520 & 0.9546 & 0.9518 & $-1.90 \mathrm{e}-041 /{ }^{\circ} \mathrm{C}$ \\
Losses $[\mathrm{W}]$ & 1.5619 & 1.5782 & 1.5775 & 1.5945 & 1.5966 & 1.5979 & $+7.01 \mathrm{e}-04 \mathrm{~W} /{ }^{\circ} \mathrm{C}$ \\
& & & & & & \\
\hline
\end{tabular}

Table 4: Box temperature, efficiency and power losses average and maximal values for each of the converter placement scenarios. Temperature-coefficients are determined for the power losses and the efficiency, given on the right.

(i.e. the difference between the daily maximum and minimum and the maximum itself) show that the temperature developed inside the converter case changes significantly. Assuming that the converter is placed in the top part of the frame, the losses will be approximately $1.5 \%$ higher compared to indoor placement 


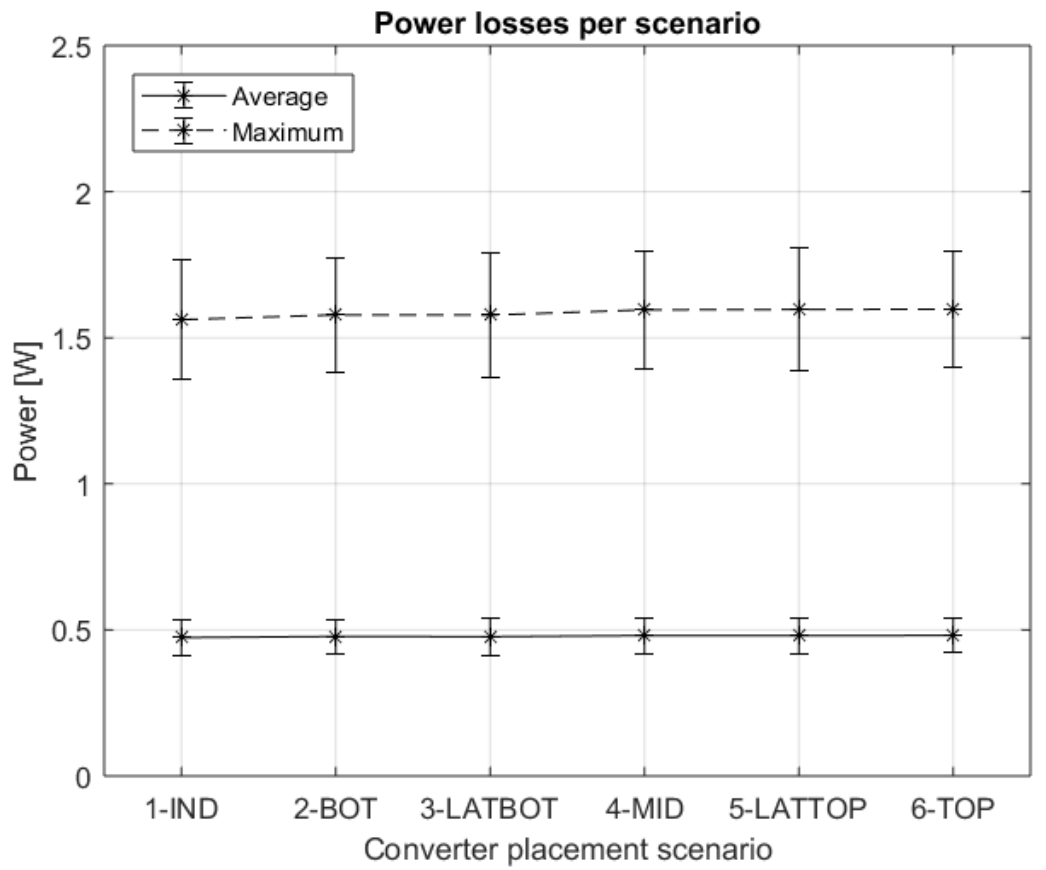

Figure 8: Average and maximal values of the converter power losses estimated for each of the placement scenarios.

outside the BIPV module frame. The impact on the efficiency will not exceed the level of $0.3 \%$. However, in scenario 6 the temperature spread increased by $1100 \%$, the average temperature by approximately $40 \%$ and the maximum temperature by $200 \%$ compared to scenario 1 . Figure 9 includes the error bars based on MRE values derived in from the validation. As shown, it is safe to assume that converter placement has a decisive impact on the temperature-related KPI. The importance of those KPI is substantial as they have significant impact on the lifetime of the converter's components and therefore on the system's overall reliability, maintainability and net present value (NPV).

\subsection{Distribution of converter losses}

The second part of this case study investigates the distribution of the power losses within the converter, i.e. the extent of the contribution of each component to the total power losses. In addition, the study investigates further these losses within each component. For example, the losses in the switch are due to switching, but also conduction, while the losses in the inductor are a combination of DC and AC resistive losses and core losses. For each of the scenarios depicted on Figure 1, the losses breakdown per component and contributing factor are estimated and given in Table 5 and Figure A.19. This study provides 


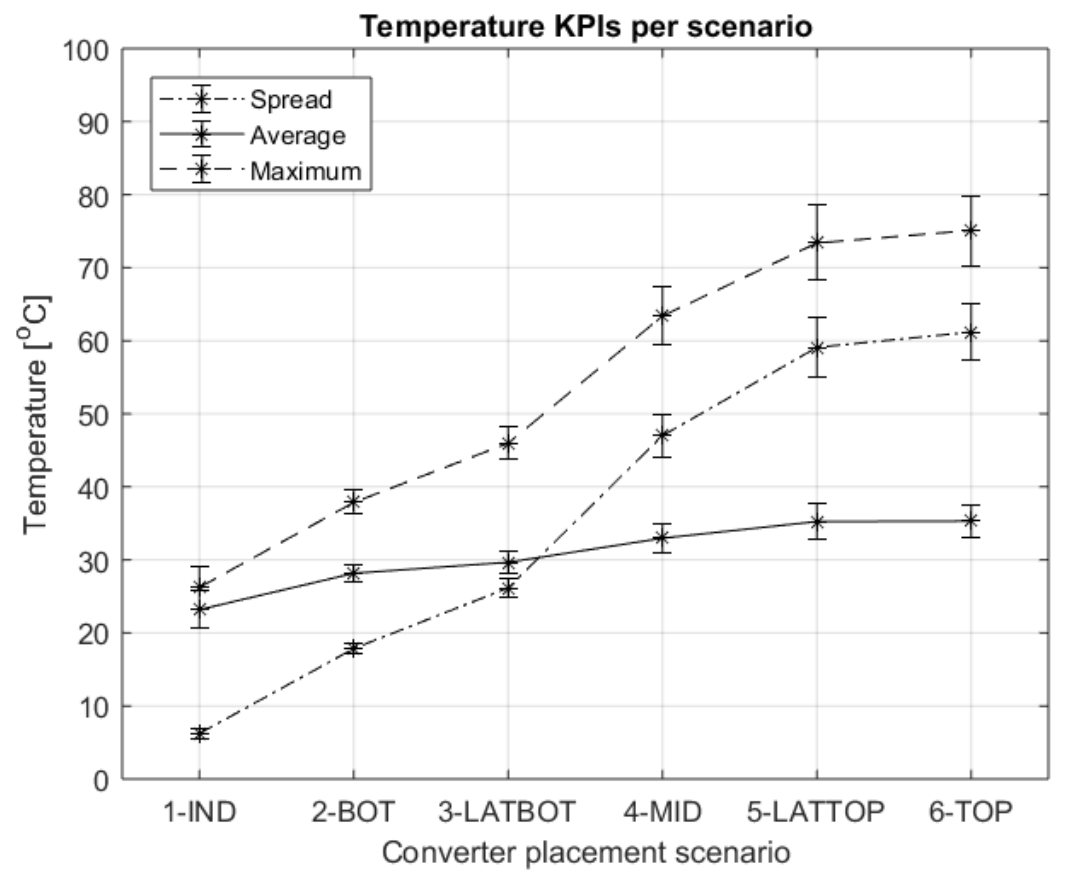

Figure 9: Average, spread and maximal values of the converter box temperature, $T_{b o x}$, estimated for each of the placement scenarios.

an estimation of the losses breakdown coupled to the operating conditions of the converter, i.e. the electrical loading and the surrounding temperature. The model can provide valuable input to the design process of such power converters. Depending on the application, the electrical load and surrounding temperature profiles the most pertinent loss contributors are identified. From a simulation perspective, the required level of detail varies among simulations with different scope. The results of this study provide a quantification about which components and specific factors are the most contributing to the losses and which can be omitted from the model and what cost of accuracy.

The diode losses contribute to the converter losses by an average of approximately $77 \%$, followed by the switch losses which contribute about $14 \%$, the inductor losses with 8-9\% and finally the capacitor losses with about $1 \%$. It is found that the diode losses are reinforced by the value of the duty cycle, which was $30 \%$ for this experiment. As expected, the capacitor losses contribute minimally to the total losses and are often disregarded in several studies which is supported by this finding. Concerning the inductor in particular, it is found that its losses comprise mostly of the $\mathrm{DC}$ resistive losses. The $\mathrm{AC}$ resistive losses account for approximately $6 \%$ of the inductor losses or $0.5 \%$ of the total converter losses and, since their estimation may be complex, they can be 
omitted to a minor cost in accuracy. The inductor core losses are negligible as shown in Table 5. Unlike the other components, the inductor losses seem to be more sensitive to higher temperatures with an increase by $11 \%$ when the converter is placed in the warmer top side of the frame compared to being placed indoors. The switch and diode losses seem to be affected mainly by switching and conduction losses, respectively, and their contribution does not seem to be influenced by the temperature as observed in Table 5 .

\begin{tabular}{cccccccc}
\hline KPI & 1-IND & 2-BOT & 3-LATBOT & 4-MID & 5-LATTOP & 6 -TOP & Unit \\
\hline \multicolumn{7}{c}{ Converter losses } \\
\hline Total & $\mathbf{1 1 . 3 7}$ & $\mathbf{1 1 . 4 6}$ & $\mathbf{1 1 . 4 5}$ & $\mathbf{1 1 . 5 4}$ & $\mathbf{1 1 . 5 3}$ & $\mathbf{1 1 . 5 5}$ & $\mathbf{W h}$ \\
Inductor & 7.86 & 8.12 & 8.23 & 8.52 & 8.67 & 8.68 & $\%$ \\
Capacitor & 1.13 & 1.16 & 1.18 & 1.22 & 1.24 & 1.24 & $\%$ \\
Switch & 13.44 & 13.50 & 13.43 & 13.56 & 13.45 & 13.60 & $\%$ \\
Diode & 77.6 & 77.22 & 77.17 & 76.70 & 76.63 & 76.47 & $\%$ \\
\hline \multicolumn{7}{c}{ Inductor losses } \\
\hline Total & $\mathbf{0 . 8 9}$ & $\mathbf{0 . 9 3}$ & $\mathbf{0 . 9 4}$ & $\mathbf{0 . 9 8}$ & $\mathbf{1 . 0 0}$ & $\mathbf{1 . 0 0}$ & $\mathbf{W h}$ \\
DCR & 93.99 & 93.91 & 94.10 & 93.88 & 94.14 & 93.88 & $\%$ \\
ACR & 6.01 & 6.09 & 5.90 & 6.12 & 5.86 & 6.12 & $\%$ \\
Core & $1.4 \mathrm{e}-05$ & $1.4 \mathrm{e}-05$ & $1.3 \mathrm{e}-05$ & $1.3 \mathrm{e}-05$ & $1.2 \mathrm{e}-05$ & $1.3 \mathrm{e}-05$ & $\%$ \\
\hline \multicolumn{7}{c}{ Switch losses } \\
\hline Total & $\mathbf{1 . 5 3}$ & $\mathbf{1 . 5 5}$ & $\mathbf{1 . 5 4}$ & $\mathbf{1 . 5 6}$ & $\mathbf{1 . 5 5}$ & $\mathbf{1 . 5 7}$ & $\mathbf{W h}$ \\
Conduction & 7.88 & 8.52 & 8.58 & 9.49 & 9.64 & 9.91 & $\%$ \\
Switching & 92.12 & 91.48 & 91.42 & 90.51 & 90.36 & 90.09 & $\%$ \\
\hline & & \multicolumn{7}{c}{ Diode losses } & & \\
\hline Total & $\mathbf{8 . 8 2}$ & $\mathbf{8 . 8 5}$ & $\mathbf{8 . 8 3}$ & $\mathbf{8 . 8 5}$ & $\mathbf{8 . 8 3}$ & $\mathbf{8 . 8 3}$ & $\mathbf{W h}$ \\
Conduction & 96.61 & 96.60 & 96.62 & 96.60 & 96.63 & 96.60 & $\%$ \\
Switching & 3.39 & 3.40 & 3.38 & 3.40 & 3.37 & 3.40 & $\%$ \\
\hline
\end{tabular}

Table 5: Breakdown of the losses per component and per contributing factor. The breakdown is given for each of the scenarios presented in section 3 .

\section{Conclusions and outlook}

This paper presented an electrical-thermal model of a boost DC/DC converter implemented in Modelica. The model is compatible with existing libraries for building energy simulations and can, therefore, be used to assess the potential benefits of a BIPV system and screen the suitability of different electrical architectures for such systems. The proposed model has been validated using experimental measurements from its real life implementation on PCB using a climate chamber to emulate the conditions for each of the assessed scenarios. Additionally, the functionality of the model is demonstrated through two case studies. 
The model is able to estimate the converter's output power and current, losses and efficiency with higher accuracy compared to the power conditioner model available in TRNSYS. The proposed model is also able to estimate the converter temperature which is not an available functionality in the TRNSYS model. Furthermore, the approach adopted for the implementation of this model is characterized by low computation cost. The electrical-thermal model converges fast and a 24-hour period can be simulated within a couple of seconds, making the model well-suited for long-term simulations, often the case for BES.

As seen in the case studies, the converter losses and efficiency did not show a strong dependence on the temperature within the range of $20^{\circ} \mathrm{C}$ and $70^{\circ} \mathrm{C}$ as in the tested scenarios. However, the correlations had a positive and negative trend for power losses and efficiency respectively. Finally, the main contributors to the converter losses have been studied. A noteworthy finding is that inductor losses demonstrated a stronger positive correlation to temperature compared to the other contributors. This information may need be considered by converter designers when the converter is to be integrated in a space with high temperatures.

As a next step to the presented research, the authors have identified the main pylons for improvement. First, the heat transfer network presented in Figure 3 may be expanded to each of the converter components. As such, it will be possible to estimate the temperature of each component, since thermal imaging revealed that not all components are heated up uniformly. Second, the thermodynamic properties of the air inside a converter housing box vary depending on the temperature; while this is not reflected in the current model, it is certainly one of the aspects to be worked further. Third, to improve the ease of use of the presented model, a set of records containing the parameters of several representative power converters will be developed and added to the library. The converter temperature estimation will be further coupled to lifetime and reliability calculations providing guidelines for power converter designers. Finally, next to improving the accuracy of the converter model itself, a study dedicated to BIPV system design case studies will be considered as a means of demonstrating the BIPV simulation framework as a whole.

\section{Acknowledgements}

The research presented in this paper is part of an integrated BIPV simulation framework supported by the European Union, the European Regional Development Fund ERDF, Flanders Innovation and Entrepreneurship and the Province of Limburg. The authors would like to thank the lab staff and especially Luc Willems, Johan De Winter, Hannes De Winter and Gert Verbeek for supporting the experimental part of this work. 


\section{Nomenclature and acronyms}

\begin{tabular}{|ll|}
\hline Symbol & Meaning \\
\hline$A$ & Converter housing box surface \\
$B_{p}$ & Inductor peak flux density \\
$C_{b o x}$ & Converter housing box thermal capacitance \\
$C_{G D}$ & Gate-drain capacitance \\
$f_{s}$ & Switching frequency \\
$h_{c}$ & Converter housing box convective heat transfer coefficient \\
$I_{C, \text { rms }}$ & Capacitor RMS current \\
$I_{D, \text { avg }}$ & Diode average current \\
$I_{D, r m s}$ & Diode RMS current \\
$I_{\text {in }}$ & Converter input current \\
$I_{L}$ & Inductor current \\
$I_{o}$ & Converter output current \\
$I_{S, \text { on }}$ & Switch on-state current \\
$I_{S, \text { off }}$ & Switch off-state current \\
$I_{S, r m s}$ & Switch RMS current \\
$P_{C}$ & Capacitor losses \\
$P_{D, C o n d}$ & Diode losses due to conduction \\
$P_{D, S w}$ & Diode losses due to switching \\
$P_{L, D C R}$ & Inductor losses due to DC resistance \\
$P_{L, A C R}$ & Inductor losses due to AC resistance \\
$P_{L, \text { core }}$ & Inductor core losses \\
$P_{l o s s}$ & Converter total losses \\
$P_{o}$ & Converter output power \\
$P_{S, S w}$ & Switch losses due to switching \\
$P_{S, \text { Cond }}$ & Switch losses due to conduction \\
$Q$ & Converter housing box heat flux \\
$Q_{r r}$ & Switch reverse recovery charge \\
$R_{A C}$ & Inductor AC resistance \\
$R_{D C}$ & Inductor DC resistance \\
$R_{D S, o n}$ & Switch drain-source on-resistance \\
$R_{E S R}$ & Capacitor equivalent series resistance \\
$R_{F}$ & Diode forward resistance \\
$R_{\text {out }}$ & Converter output resistance (load) \\
$R_{\theta}$ & Converter housing box thermal resistance \\
$t_{o f f}$ & Switch off-time \\
$t_{o n}$ & Switch on-time \\
$T_{\text {box }}$ & Converter housing box temperature \\
$T_{e x t}$ & Converter housing box exterior temperature \\
$T_{j}$ & Switch junction temperature \\
$T_{s}$ & Switching period \\
$U_{D S}$ & Switch drain-source voltage \\
$U_{F}$ & Diode forward voltage \\
$U_{\text {in }}$ & Converter input voltage \\
$U_{\text {out }}$ & Converter output voltage \\
$\delta$ & Duty cycle \\
$\Delta_{L}$ & Inductor current ripple \\
$\eta$ & Converter efficiency \\
\hline
\end{tabular}




\begin{tabular}{|ll|}
\hline Acronym & Meaning \\
\hline BES & Building Energy Simulation \\
(BI)PV & (Building Integrated) PhotoVoltaic(s) \\
BOS & Balance Of System \\
CHTC & Convective heat transfer coefficient \\
ESR & Equivalent Series Resistance \\
HVAC & Heating Ventilation and Air Conditioning \\
KPI & Key Performance Indicator(s) \\
MPP(T) & Maximum Power Point (Tracking) \\
MRE & Mean Relative Error \\
NZEB & Near-Zero Energy Building(s) \\
PCB & Printed Circuit Board \\
\hline
\end{tabular}

\section{References}

[1] European Parliament and Council, Council Directive 2010/31/EU of 19 May 2010 on the energy performance of buildings, OJ L 153/13.

[2] A. K. Athienitis, G. Barone, A. Buonomano, A. Palombo, Assessing active and passive effects of façade building integrated photovoltaics/thermal systems: Dynamic modelling and simulation, Applied Energy 209 (2018) 355-382. doi:10.1016/j.apenergy.2017.09.039.

URL http://www.sciencedirect.com/science/article/pii/ S030626191731320X

[3] G. P. Lydon, J. Hofer, B. Svetozarevic, Z. Nagy, A. Schlueter, Coupling energy systems with lightweight structures for a net $\begin{array}{llllll}\text { plus energy building, Applied Energy } 189 & \text { (2017) } & 310-326 .\end{array}$ doi:10.1016/j.apenergy.2016.11.110.

URL http://www.sciencedirect.com/science/article/pii/ S030626191631741X

[4] H. Wang, W. Chen, J. Shi, Low carbon transition of global building sector under 2- and 1.5-degree targets, Applied Energy 222 (2018) 148-157. doi:10.1016/j.apenergy.2018.03.090.

URL http://www.sciencedirect.com/science/article/pii/ S030626191830429X

[5] Z. Tian, X. Zhang, X. Jin, X. Zhou, B. Si, X. Shi, Towards adoption of building energy simulation and optimization for passive building design: A survey and a review, Energy and Buildings 158 (2018) 1306-1316. doi:10.1016/j.enbuild.2017.11.022.

URL http://www.sciencedirect.com/science/article/pii/ S0378778817317899 
[6] P. Shiel, S. Tarantino, M. Fischer, Parametric analysis of design stage building energy performance simulation models, Energy and Buildings 172 (2018) 78-93. doi:10.1016/j.enbuild.2018.04.045.

URL http://www.sciencedirect.com/science/article/pii/ S0378778817334461

[7] A. M. A. Youssef, Z. J. Zhai, R. M. Reffat, Generating proper building envelopes for photovoltaics integration with shape grammar theory, Energy and Buildings 158 (2018) 326-341. doi: 10.1016/j.enbuild.2017.09.077.

URL http://www.sciencedirect.com/science/article/pii/ S0378778817319448

[8] A. Cannavale, L. Ierardi, M. Hörantner, G. E. Eperon, H. J. Snaith, U. Ayr, F. Martellotta, Improving energy and visual performance in offices using building integrated perovskite-based solar cells: A case study in Southern Italy, Applied Energy 205 (2017) 834-846. doi:10.1016/j.apenergy.2017.08.112.

URL http://wWw.sciencedirect.com/science/article/pii/ S0306261917311339

[9] A. Mariaud, S. Acha, N. Ekins-Daukes, N. Shah, C. N. Markides, Integrated optimisation of photovoltaic and battery storage systems for UK commercial buildings, Applied Energy 199 (2017) 466-478. doi:10.1016/j.apenergy.2017.04.067.

URL http://www.sciencedirect.com/science/article/pii/ S0306261917304646

[10] P. Jayathissa, M. Luzzatto, J. Schmidli, J. Hofer, Z. Nagy, A. Schlueter, Optimising building net energy demand with dynamic BIPV shading, Applied Energy 202 (2017) 726-735. doi:10.1016/j.apenergy.2017.05.083. URL http://www.sciencedirect.com/science/article/pii/ S0306261917305810

[11] Welcome | TRNSYS : Transient System Simulation Tool. URL http://www.trnsys.com/

[12] EnergyPlus, EnergyPlus | EnergyPlus.

URL https://energyplus.net/

[13] S. R. Asaee, S. Nikoofard, V. I. Ugursal, I. Beausoleil-Morrison, Techno-economic assessment of photovoltaic (PV) and building integrated photovoltaic/thermal (BIPV/T) system retrofits in the Canadian housing stock, Energy and Buildings 152 (2017) 667-679. doi:10.1016/j.enbuild.2017.06.071.

URL http://www.sciencedirect.com/science/article/pii/ S0378778816319892 
[14] R. S. Kamel, A. S. Fung, Modeling, simulation and feasibility analysis of residential BIPV/T+ASHP system in cold climate - Canada, Energy and Buildings 82 (2014) 758-770. doi:10.1016/j.enbuild.2014.07.081. URL http://www.sciencedirect.com/science/article/pii/ S0378778814006306

[15] E. Vuong, R. S. Kamel, A. S. Fung, Modelling and Simulation of BIPV/T in EnergyPlus and TRNSYS, Energy Procedia 78 (2015) 1883-1888. doi:10.1016/j.egypro.2015.11.354.

URL http://www.sciencedirect.com/science/article/pii/ S187661021502086X

[16] E. Biyik, M. Araz, A. Hepbasli, M. Shahrestani, R. Yao, L. Shao, E. Essah, A. C. Oliveira, T. del Caño, E. Rico, J. L. Lechón, L. Andrade, A. Mendes, Y. B. Atll, A key review of building integrated photovoltaic (BIPV) systems, Engineering Science and Technology, an International Journal 20 (3) (2017) 833-858. doi:10.1016/j.jestch.2017.01.009.

URL http://www.sciencedirect.com/science/article/pii/ S2215098616309326

[17] M. Wetter, M. Bonvini, T. Nouidui, Equation-based languages-a new paradigm for building energy modeling, simulation and optimization, Energy and Buildings 117 (2016) 290-300. doi:10.1016/j.enbuild.2015. 10.017

[18] A. Maccarini, M. Wetter, A. Afshari, G. Hultmark, N. C. Bergsøe, A. Vorre, Energy saving potential of a two-pipe system for simultaneous heating and cooling of office buildings, Energy and Buildings 134 (2017) 234-247. doi:10.1016/j.enbuild.2016.10.051.

URL http://www.sciencedirect.com/science/article/pii/ S0378778816313731

[19] D. W. U. Perera, D. Winkler, N. O. Skeie, Multi-floor building heating models in MATLAB and Modelica environments, Applied Energy 171 (2016) 46-57. doi:10.1016/j.apenergy .2016.02.143.

URL http://www.sciencedirect.com/science/article/pii/ S0306261916303099

[20] A. Andriamamonjy, D. Saelens, R. Klein, An automated IFCbased workflow for building energy performance simulation with Modelica Automation in Construction 91 (2018) 166-181. doi:10.1016/j. autcon.2018.03.019.

URL http://www.sciencedirect.com/science/article/pii/ S0926580517308282

[21] M. Wetter, W. Zuo, T. S. Nouidui, X. Pang, Modelica Buildings library, Journal of Building Performance Simulation 7 (4) (2014) 253-270. doi: 10.1080/19401493.2013.765506.

URL https://doi.org/10.1080/19401493.2013.765506 
[22] H. P. Ikkurti, S. Saha, A comprehensive techno-economic review of microinverters for Building Integrated Photovoltaics (BIPV), Renewable and Sustainable Energy Reviews 47 (2015) 997-1006. doi:10.1016/j.rser.2015.03.081

URL http://www.sciencedirect.com/science/article/pii/ S1364032115002348

[23] S. Wittkopf, S. Valliappan, L. Liu, K. S. Ang, S. C. J. Cheng, Analytical performance monitoring of a 142.5kwp grid-connected rooftop BIPV system in Singapore, Renewable Energy 47 (2012) 9-20. doi:10.1016/j.renene.2012.03.034.

URL http://www.sciencedirect.com/science/article/pii/ S0960148112002352

[24] M. Patel, H. Surati, J. Patel, Modelling and simulation of photovoltaic module for micro inverter application, in: 2017 International Conference on Trends in Electronics and Informatics (ICEI), 2017, pp. 82-85. doi: 10.1109/ICOEI.2017.8300820.

[25] S. N. Shetty, M. A. Raheman, Modelling of dual input DC/DC converter for hybrid energy system, in: 2017 2nd IEEE International Conference on Recent Trends in Electronics, Information Communication Technology (RTEICT), 2017, pp. 1152-1155. doi:10.1109/RTEICT. 2017.8256779.

[26] M. K. Ahmad, M. S. Ali, A. Majid, J. Saleem, S. M. R. Kazmi, Design and optimization of high frequency $(250 \mathrm{kHz})$ planar transformer for micro solar converter application, in: 2018 IEEE 12th International Conference on Compatibility, Power Electronics and Power Engineering (CPEPOWERENG 2018), 2018, pp. 1-6. doi:10.1109/CPE. 2018.8372533.

[27] M. S. M. Lim, S. H. M. Ali, S. Jahariah, M. S. Islam, M. S. M. Lim, Modelling of hybrid energy harvester with DC-DC boost converter using arbitary input sources for ultra-low-power micro-devices, in: 2014 IEEE International Conference on Semiconductor Electronics (ICSE2014), 2014, pp. 28-31. doi:10.1109/SMELEC.2014.6920787.

[28] A. K. Shukla, K. Sudhakar, P. Baredar, Recent advancement in BIPV product technologies: A review, Energy and Buildings 140 (2017) 188-195. doi:10.1016/j.enbuild.2017.02.015.

URL http://www.sciencedirect.com/science/article/pii/ S0378778816316528

[29] F. Jorissen, G. Reynders, R. Baetens, D. Picard, D. Saelens, L. Helsen, Implementation and verification of the IDEAS building energy simulation library, Journal of Building Performance Simulation 0 (0) (2018) 1-20. doi:10.1080/19401493.2018.1428361, URL https://doi .org/10.1080/19401493.2018.1428361 
[30] C. Zomer, R. Rüther, Simplified method for shading-loss analysis in bipv systems-part 1: Theoretical study, Energy and Buildings 141 (2017) 69-82.

[31] A. Woyte, J. Nijs, R. Belmans, Partial shadowing of photovoltaic arrays with different system configurations: literature review and field test results, Solar energy 74 (3) (2003) 217-233.

[32] R. Moretón, E. Lorenzo, L. Narvarte, Experimental observations on hotspots and derived acceptance/rejection criteria, Solar energy 118 (2015) $28-40$.

[33] P. Defaix, W. Van Sark, E. Worrell, E. de Visser, Technical potential for photovoltaics on buildings in the eu-27, Solar Energy 86 (9) (2012) 26442653.

[34] A. Chatzipanagi, F. Frontini, A. Virtuani, BIPV-temp: A demonstrative Building Integrated Photovoltaic installation, Applied Energy 173 (2016) 1-12. doi:10.1016/j.apenergy.2016.03.097.

URL http://www.sciencedirect.com/science/article/pii/ S0306261916304299

[35] S. Poshtkouhi, A. Biswas, O. Trescases, DC-DC converter for high granularity, sub-string MPPT in photovoltaic applications using a virtualparallel connection, in: 2012 Twenty-Seventh Annual IEEE Applied Power Electronics Conference and Exposition (APEC), 2012, pp. 86-92. doi: 10.1109/APEC.2012.6165802.

[36] N. Femia, G. Lisi, G. Petrone, G. Spagnuolo, M. Vitelli, Distributed maximum power point tracking of photovoltaic arrays: Novel approach and system analysis, IEEE Transactions on Industrial Electronics 55 (7) (2008) 2610-2621. doi:10.1109/TIE.2008.924035

[37] L. Linares, R. W. Erickson, S. MacAlpine, M. Brandemuehl, Improved Energy Capture in Series String Photovoltaics via Smart Distributed Power Electronics, in: 2009 Twenty-Fourth Annual IEEE Applied Power Electronics Conference and Exposition, 2009, pp. 904-910. doi:10.1109/APEC. 2009.4802770 .

[38] G. R. Walker, J. C. Pierce, Photovoltaic DC-DC module integrated converter for novel cascaded and bypass grid connection topologies - Design and optimization, in: 2006 37th IEEE Power Electronics Specialists Conference, 2006, pp. 1-7. doi:10.1109/pesc.2006.1712242.

[39] R. Bradai, R. Boukenoui, A. Kheldoun, H. Salhi, M. Ghanes, J.-P. Barbot, A. Mellit, Experimental assessment of new fast MPPT algorithm for PV systems under non-uniform irradiance conditions, Applied Energy 199 (2017) 416-429. doi:10.1016/j.apenergy.2017.05.045.

URL http://www.sciencedirect.com/science/article/pii/ S0306261917305445 
[40] H. P. Ikkurti, S. Saha, A comprehensive techno-economic review of microinverters for building integrated photovoltaics (bipv), Renewable and Sustainable Energy Reviews 47 (2015) 997-1006.

[41] G. M. Goetzler, W., M. Droesch, Research and development needs for building-integrated solar technologies (2014).

[42] S. M. Burgun, F., A. Sproul, Pv as an integrated building material: Status report, barriers and opportunities (2015).

[43] R. J. Yang, Overcoming technical barriers and risks in the application of building integrated photovoltaics (bipv): hardware and software strategies, Automation in Construction 51 (2015) 92-102.

[44] T. Yang, A. K. Athienitis, A review of research and developments of building-integrated photovoltaic/thermal (bipv/t) systems, Renewable and Sustainable Energy Reviews 66 (2016) 886-912.

[45] G. C. Lopes, R. Vicente, M. Azenha, T. M. Ferreira, A systematic review of prefabricated enclosure wall panel systems: focus on technology driven for performance requirements, Sustainable Cities and Society.

[46] A. D. Lee, P. Shepherd, M. C. Evernden, D. Metcalfe, Optimizing the architectural layouts and technical specifications of curtain walls to minimize use of aluminium, in: Structures, Vol. 13, Elsevier, 2018, pp. 8-25.

[47] A. D. Lee, P. Shepherd, M. C. Evernden, D. Metcalfe, Optimizing the crosssectional shapes of extruded aluminium structural members for unitized curtain wall facades, in: Structures, Vol. 10, Elsevier, 2017, pp. 147-156.

[48] M. Arifujjaman, M. T. Iqbal, J. E. Quaicoe, Reliability analysis of grid connected small wind turbine power electronics, Applied Energy 86 (9) (2009) 1617-1623. doi:10.1016/j.apenergy.2009.01.009.

URL http://wwW.sciencedirect.com/science/article/pii/ S0306261909000117

[49] J. E. Goncalves, J. Lehman, G. Yordanov, K. Baert, D. Saelens, Experimental performance of a curtain wall bipv element under realistic boundary conditions, in: EUPVSEC 2018, European PV Solar Energy Conference and Exhibition, 2018.

[50] F. Cellier, C. Clauss, A. Urquia, Electronic circuit modeling and simulation in Modelica, in: Proceedings EUROSIM 2007, 2007.

[51] M. Wetter, Modelica-based modelling and simulation to support research and development in building energy and control systems, Journal of Building Performance Simulation 2(2) (2009) 143-161. doi:10.1080/ 19401490902818259. 
[52] K. Majetta, S. Boehme, C. Clauss, P. Schneider, SPICE3 Modelica library, in: Proceedings of the 7th International Modelica Conference, 2009.

[53] W. Tian, T. A. Sevilla, W. Zuo, M. D. Sohn, Coupling fast fluid dynamics and multizone airflow models in Modelica Buildings library to simulate the dynamics of HVAC systems, Building and Environment 122 (2017) 269-286. doi:10.1016/j.buildenv.2017.06.013. URL http://www.sciencedirect.com/science/article/pii/ S0360132317302470

[54] X. Pang, M. Wetter, P. Bhattacharya, P. Haves, A framework for simulation-based real-time whole building performance assessment, Building and Environment 54 (2012) 100-108. doi: 10.1016/j.buildenv.2012.02.003

URL http://www.sciencedirect.com/science/article/pii/ S036013231200042X

[55] R. Baetens, R. De Coninck, J. Van Roy, B. Verbruggen, J. Driesen, L. Helsen, D. Saelens, Assessing electrical bottlenecks at feeder level for residential net zero-energy buildings by integrated system simulation, Applied Energy 96 (2012) 74-83. doi:10.1016/j.apenergy.2011.12.098

[56] P. Fritzson, Principles of Object-Oriented modeling and simulation with Modelica 2.1, Wiley, Hoboken, New Jersey, 2004.

[57] J. Channegowda, B. Saritha, H. R. Chola, G. Narayanan, Comparative evaluation of switching and average models of a DC-DC boost converter for real-time simulation, in: 2014 IEEE International Conference on Electronics, Computing and Communication Technologies (CONECCT), 2014, pp. 1-6. doi:10.1109/CONECCT.2014.6740360.

[58] N. Mohan, T. Undeland, W. Robbins, Power Electronics: converters, applications and design, Wiley, Hoboken, New Jersey, 2003.

[59] D. G, S. N. Singh, Selection of non-isolated DC-DC converters for solar photovoltaic system, Renewable and Sustainable Energy Reviews 76 (2017) 1230-1247. doi:10.1016/j.rser.2017.03.130,

URL http://wWW.sciencedirect.com/science/article/pii/ S1364032117304653

[60] N. Tewari, V. T. Sreedevi, A novel single switch dc-dc converter with high voltage gain capability for solar PV based power generation systems, Solar Energy 171 (2018) 466-477. doi:10.1016/j.solener.2018.06.081.

URL http://www.sciencedirect.com/science/article/pii/ S0038092X18306327

[61] H. Fathabadi, Novel high efficiency DC/DC boost converter for using in photovoltaic systems, Solar Energy 125 (2016) $22-31$. doi:10.1016/j.solener.2015.11.047. 
URL http://www.sciencedirect.com/science/article/pii/ S0038092X15006702

[62] A. Amir, H. S. Che, A. Amir, A. El Khateb, N. A. Rahim, Transformerless high gain boost and buck-boost DC-DC converters based on extendable switched capacitor (SC) cell for stand-alone photovoltaic system, Solar Energy 171 (2018) 212-222. doi:10.1016/j.solener.2018.06.078. URL http://www.sciencedirect.com/science/article/pii/ S0038092X18306297

[63] C. Wang, R. Xiong, H. He, X. Ding, W. Shen, Efficiency analysis of a bidirectional DC/DC converter in a hybrid energy storage system for plug-in hybrid electric vehicles, Applied Energy 183 (2016) 612-622. doi:10.1016/j.apenergy.2016.08.178.

URL http://www.sciencedirect.com/science/article/pii/ S0306261916312879

[64] D. D. Graovac, M. Pürschel, A. Kiep, MOSFET Power Losses Calculation Using the Data- Sheet Parameters (2006) 23.

[65] P. L. Dowell, Effects of eddy currents in transformer windings, Proceedings of the Institution of Electrical Engineers 113 (8) (1966) 1387-1394. doi:10.1049/piee.1966.0236.

URL http://digital-library.theiet.org/content/journals/10. 1049/piee.1966.0236

[66] Q. Chen, R.-H. Fu, Y.-C. Xu, Electrical circuit analogy for heat transfer analysis and optimization in heat exchanger networks, Applied Energy 139 (2015) 81-92. doi:10.1016/j.apenergy . 2014.11.021.

URL http://www.sciencedirect.com/science/article/pii/ S0306261914011702

[67] F. Blaabjerg, M. Liserre, K. Ma, Power Electronics Converters for Wind Turbine Systems, IEEE Transactions on Industry Applications 48 (2) (2012) 708-719. doi:10.1109/TIA.2011.2181290

[68] S. Obyn, G. van Moeseke, Variability and impact of internal surfaces convective heat transfer coefficients in the thermal evaluation of office buildings, Applied Thermal Engineering 87 (2015) 258-272. doi:10.1016/j.applthermaleng.2015.05.030.

URL http://wWw.sciencedirect.com/science/article/pii/ S1359431115004755

[69] X. Chen, Q. Wang, J. Srebric, Occupant feedback based model predictive control for thermal comfort and energy optimization: A chamber experimental evaluation, Applied Energy 164 (2016) 341-351. doi:10.1016/j.apenergy.2015.11.065.

URL http://www.sciencedirect.com/science/article/pii/ S0306261915015159 
[70] P. A. Fokaides, A. Jurelionis, L. Gagyte, S. A. Kalogirou, Mock target IR thermography for indoor air temperature measurement, Applied Energy 164 (2016) 676-685. doi:10.1016/j.apenergy.2015.12.025. URL http://www.sciencedirect.com/science/article/pii/ S0306261915015986

[71] S. Ravyts, M. Dalla Vecchia, J. Zwysen, G. Van den Broeck, J. Driesen, Comparison between an interleaved boost converter using si mosfets versus gan hemts, in: PCIM Europe 2018, International Exhibition and Conference for Power Electronics, Intelligent Motion, Renewable Energy and Energy Management, 2018.

[72] G. Leone, M. Beccali, Use of finite element models for estimating thermal performance of façade-integrated solar thermal collectors, Applied Energy 171 (2016) 392-404. doi:10.1016/j.apenergy. 2016.03.039.

URL http://www.sciencedirect.com/science/article/pii/ S0306261916303518

[73] J. Nakos, Uncertainty analysis of thermocouple measurements used in normal and abnormal thermal environment experiments at sandia's radiant heat facility and lurance canyon burn site (2004).

[74] S.A. Klein and J.A. Duffie and J.C. Mitchell and J.P. Kumer and J.W. Thornton and D.E. Bradley and D.A. Arias and W.A. Beckman and N.A. Duffie and J.E. Braun, TRNSYS 17 Mathematical Refererence, http://web.mit.edu/parmstr/Public/TRNSYS/ 04-MathematicalReference.pdf (2017).

[75] K. Ma, M. Liserre, F. Blaabjerg, T. Kerekes, Thermal Loading and Lifetime Estimation for Power Device Considering Mission Profiles in Wind Power Converter, IEEE Transactions on Power Electronics 30 (2) (2015) 590-602. doi:10.1109/TPEL.2014.2312335.

[76] W. V. D. Sande, M. Daenen, K. Spiliotis, J. Gonçalves, S. Ravyts, D. Saelens, J. Driesen, Reliability Comparison of a DC-DC Converter Placed in Building-Integrated Photovoltaic Module Frames, in: 2018 7th International Conference on Renewable Energy Research and Applications (ICRERA), 2018, pp. 412-417. doi:10.1109/ICRERA.2018.8566709.

\section{Appendix A. Schematics}




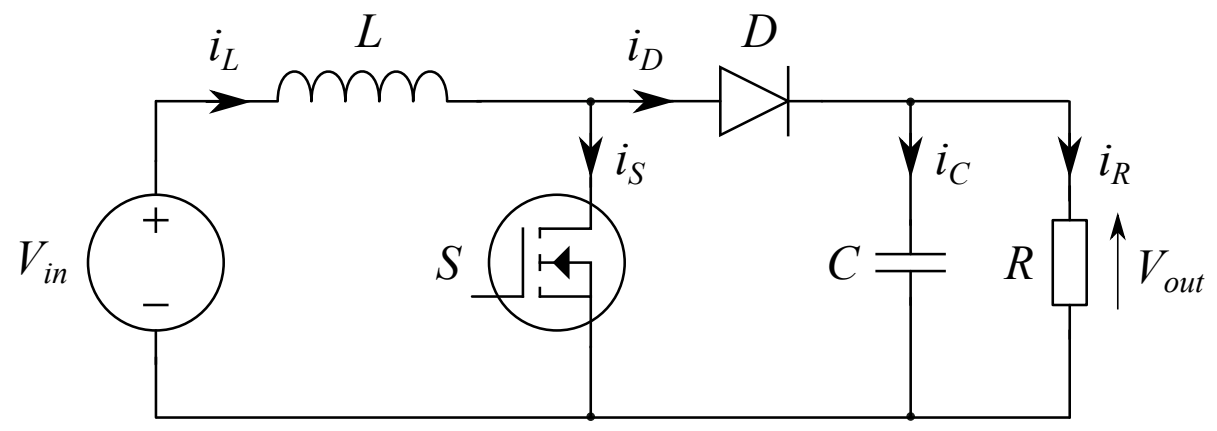

Figure A.10: A typical boost DC/DC converter topology consisting of the switching cell and the passive components.
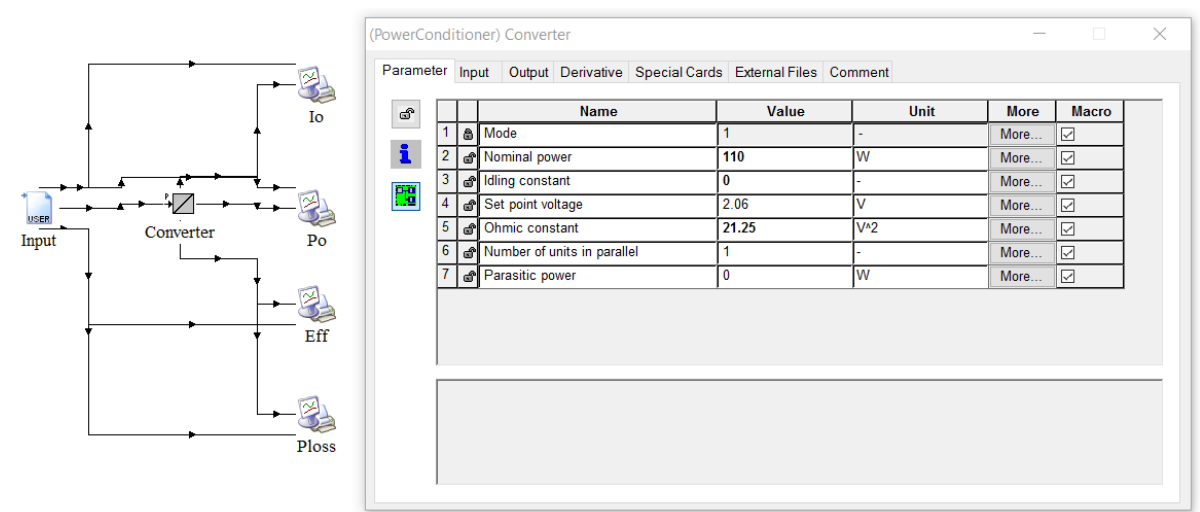

Figure A.11: Screen shot from Simulation Studio, where TRNSYS Type 175 power conditioner is used for the benchmark described in 3.3. A Type 9 block is used to feed the input to the converter (input and output voltage, input power) and several Type 65 blocks are used to obtain the simulated outpu'ots from the converter (output current, power, efficiency and losses). 

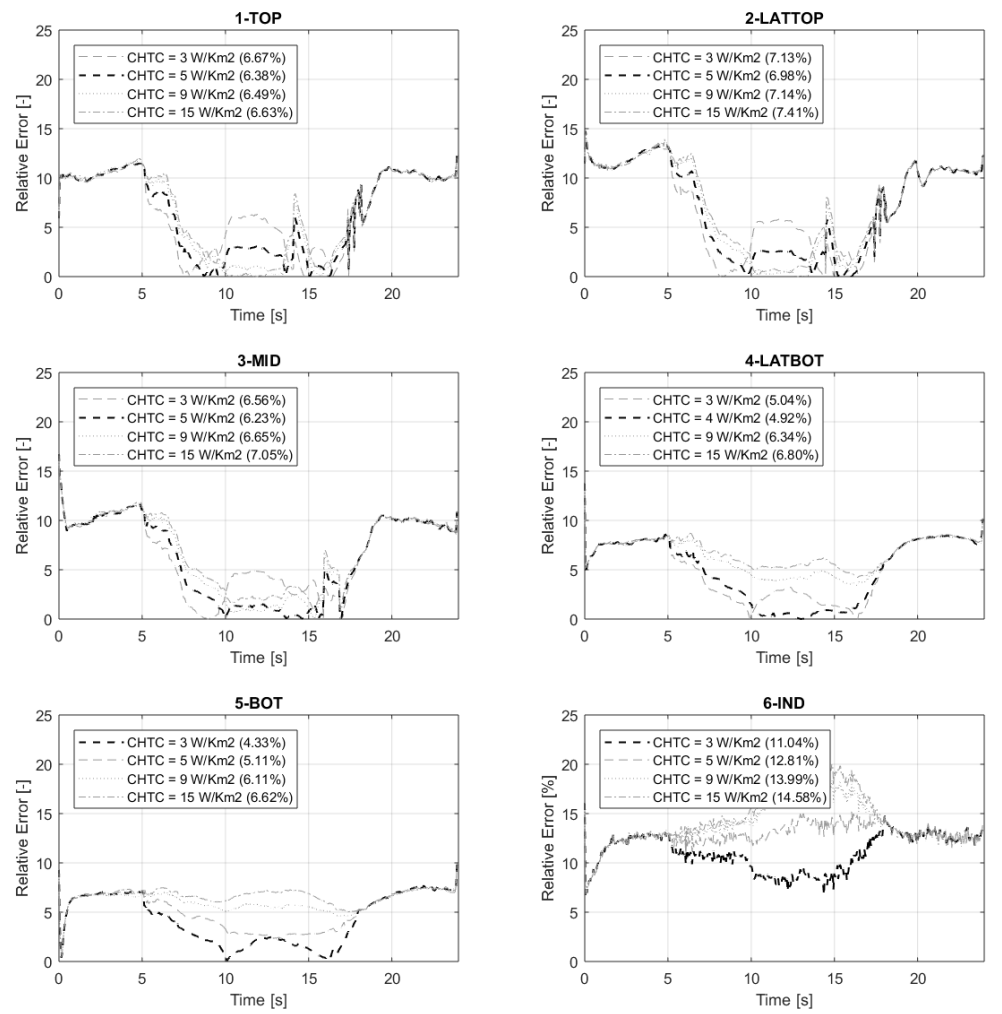

Figure A.12: Relative error (RE) between estimated and measured $T_{b o x}$ for different CHTC for each of the assessed positions. The CHTC values that minimize the RE are illustrated in thick black lines. 


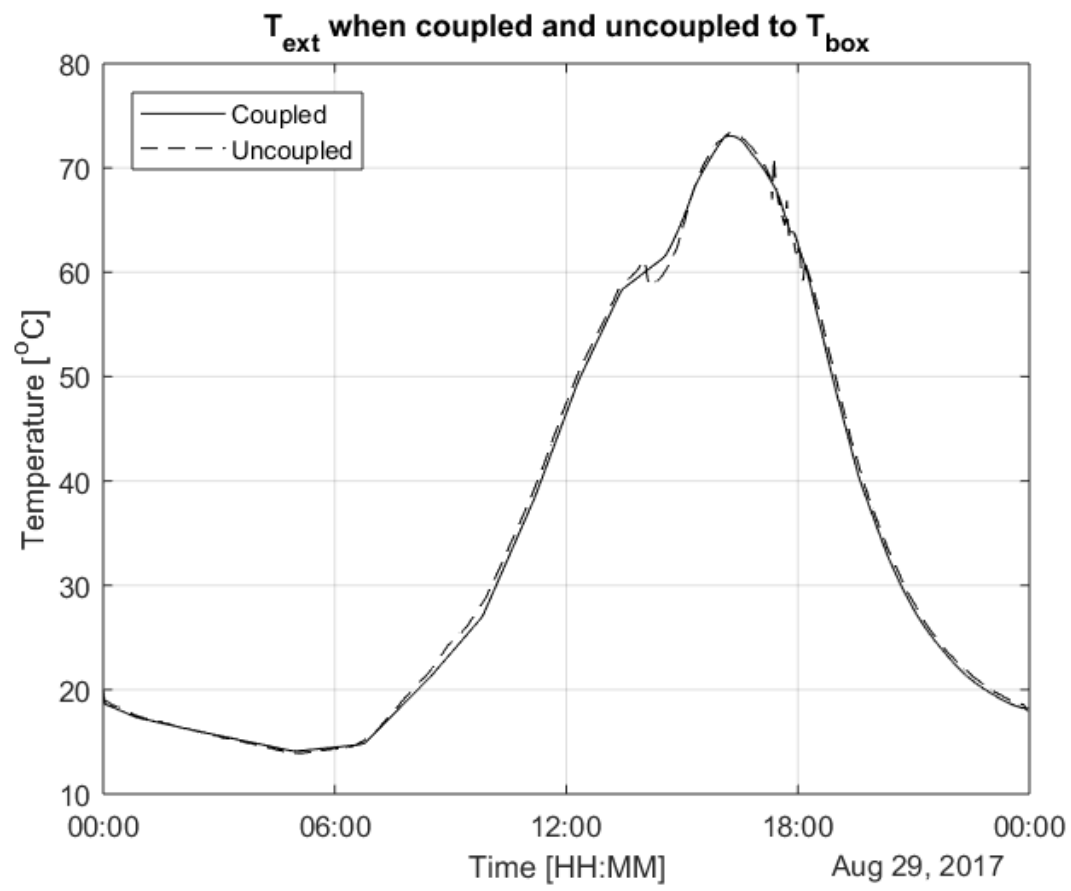

Figure A.13: The temperature inside the BIPV frame coupled and decoupled to the converter shows a mean deviation of $0.5^{\circ} \mathrm{C}$. It can be assumed that the interior frame temperature is a boundary condition for the converter. 

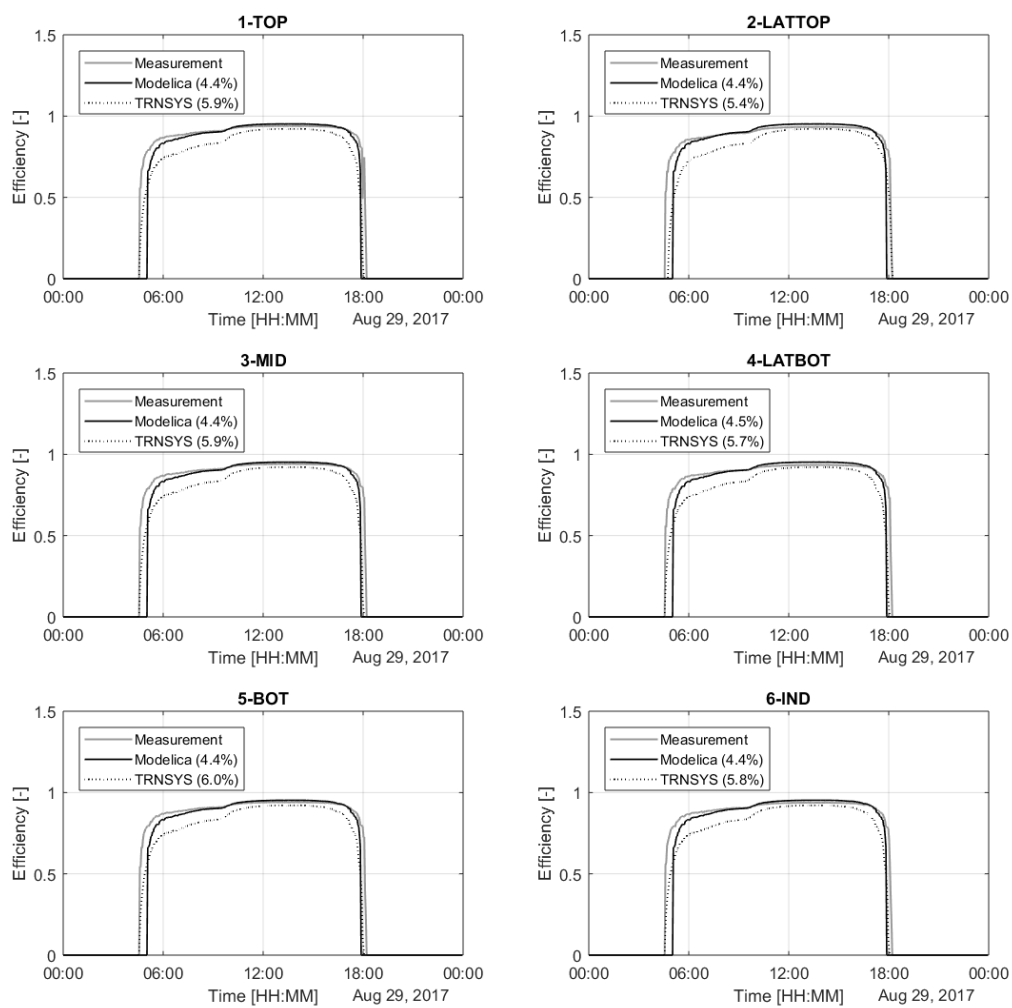

Figure A.14: Efficiency curves estimated with the proposed model (black) and the TRNSYS model (dashed) next to the experimental measurements (gray) for each placement scenario. 

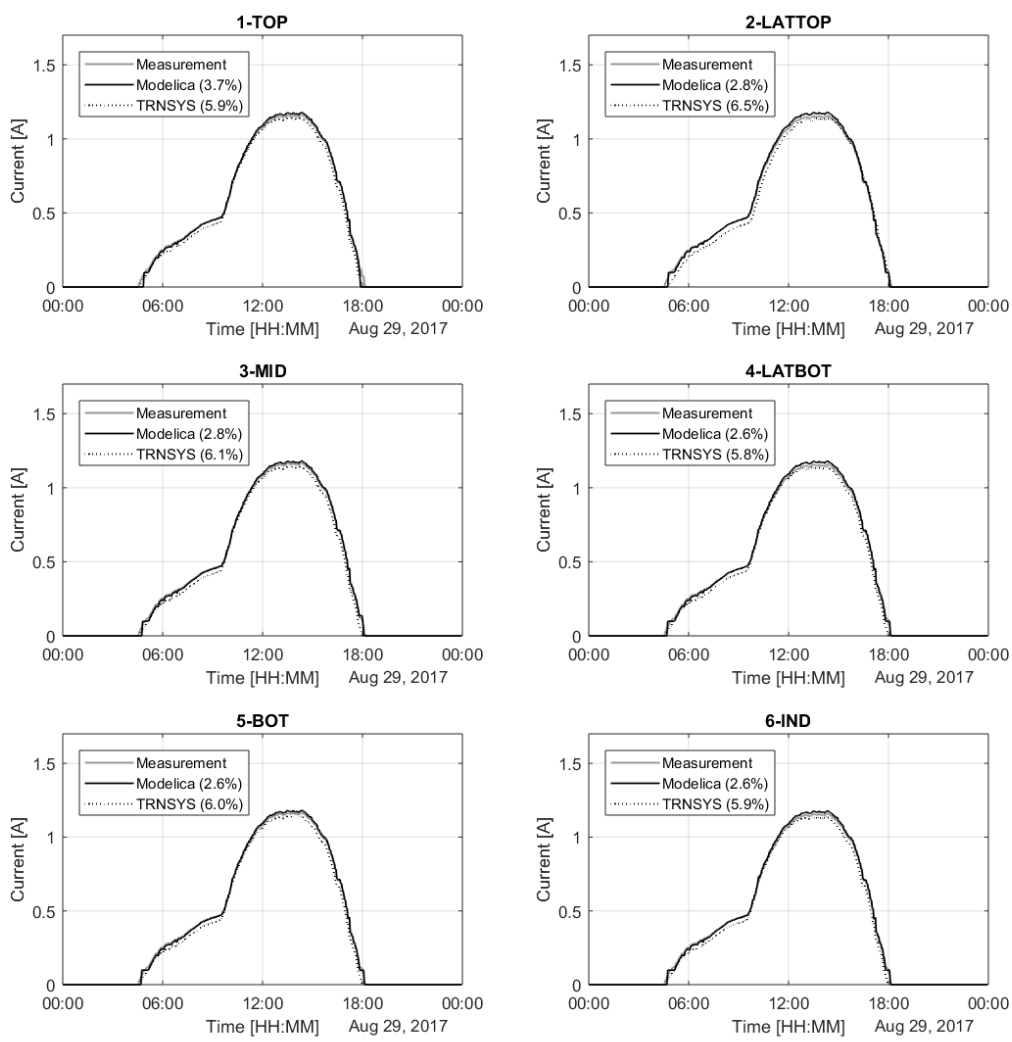

Figure A.15: Converter output current curves estimated with the proposed model (black) and the TRNSYS model (dashed) next to the experimental measurements (gray) for each placement scenario. 

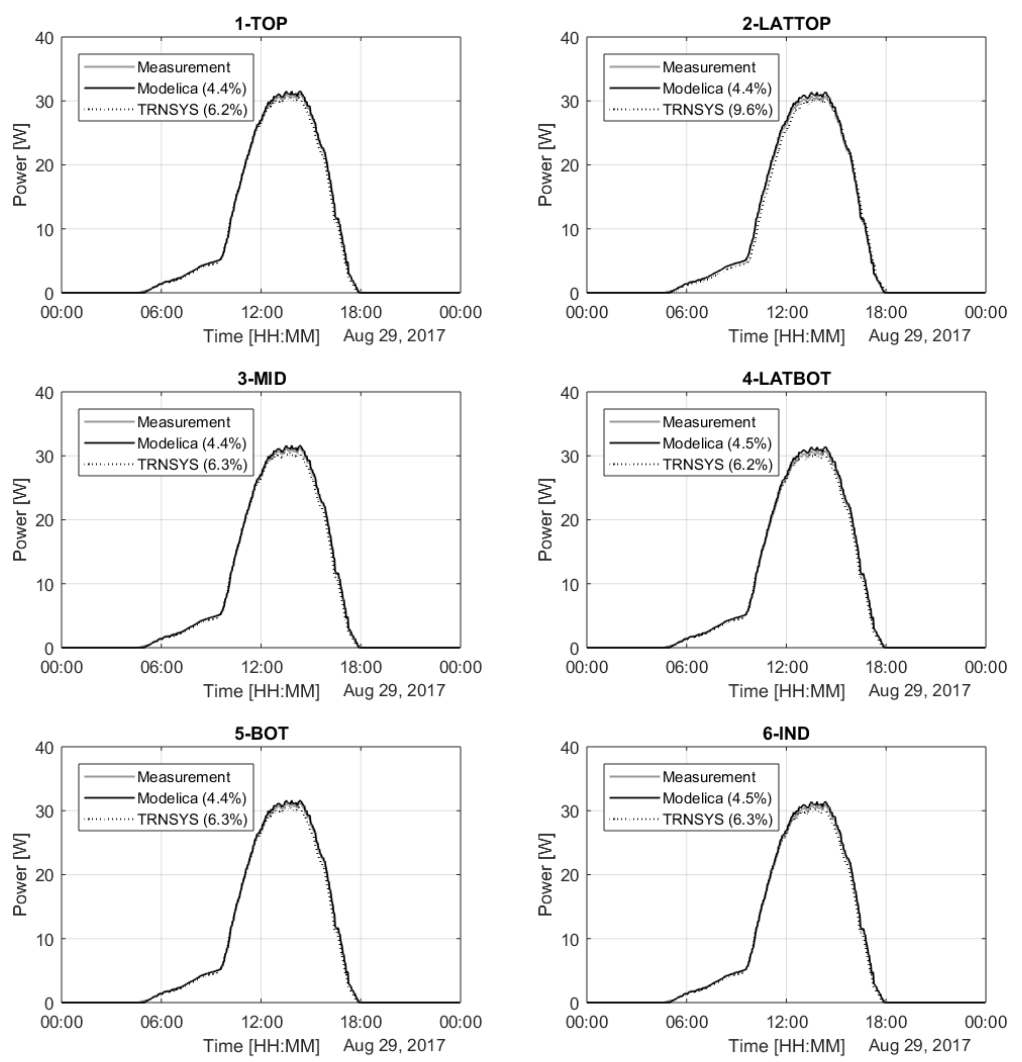

Figure A.16: Converter output power curves estimated with the proposed model (black) and the TRNSYS model (dashed) next to the experimental measurements (gray) for each placement scenario. 

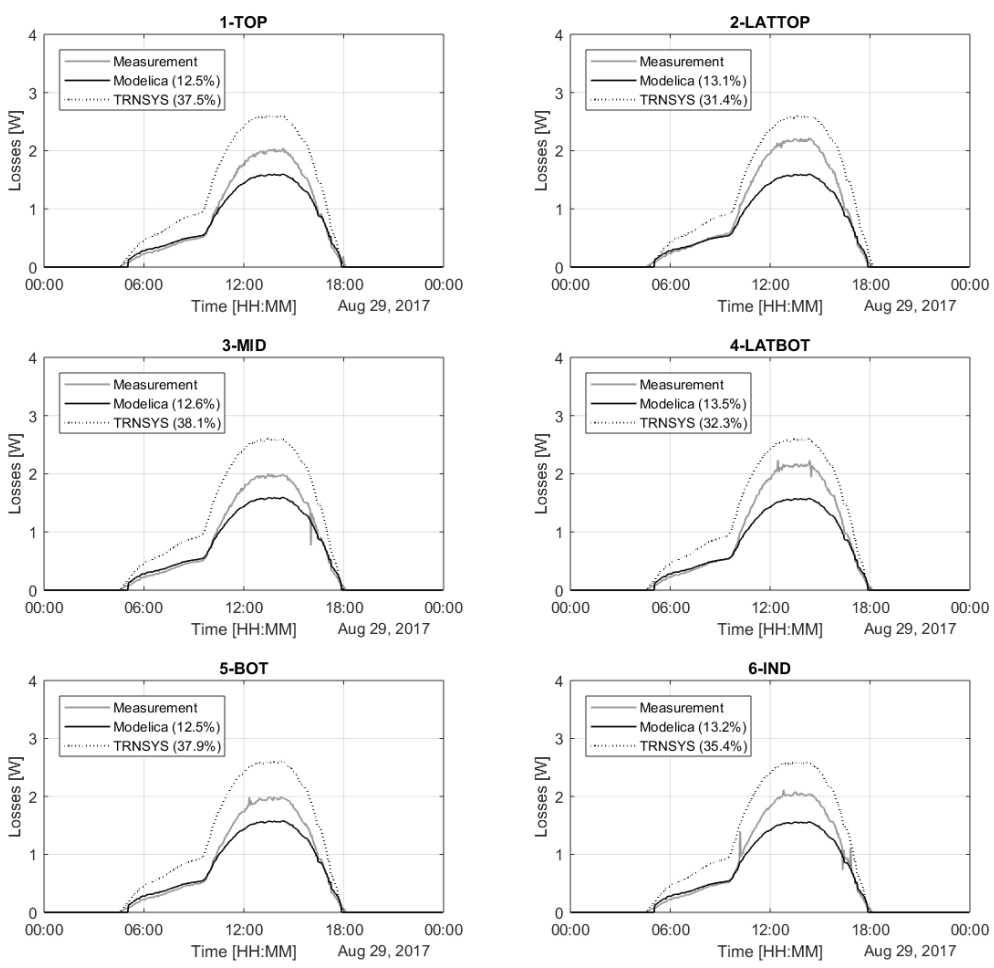

Figure A.17: Converter loss curves estimated with the proposed model (black) and the TRNSYS model (dashed) next to the experimental measurements (gray) for each placement scenario. 

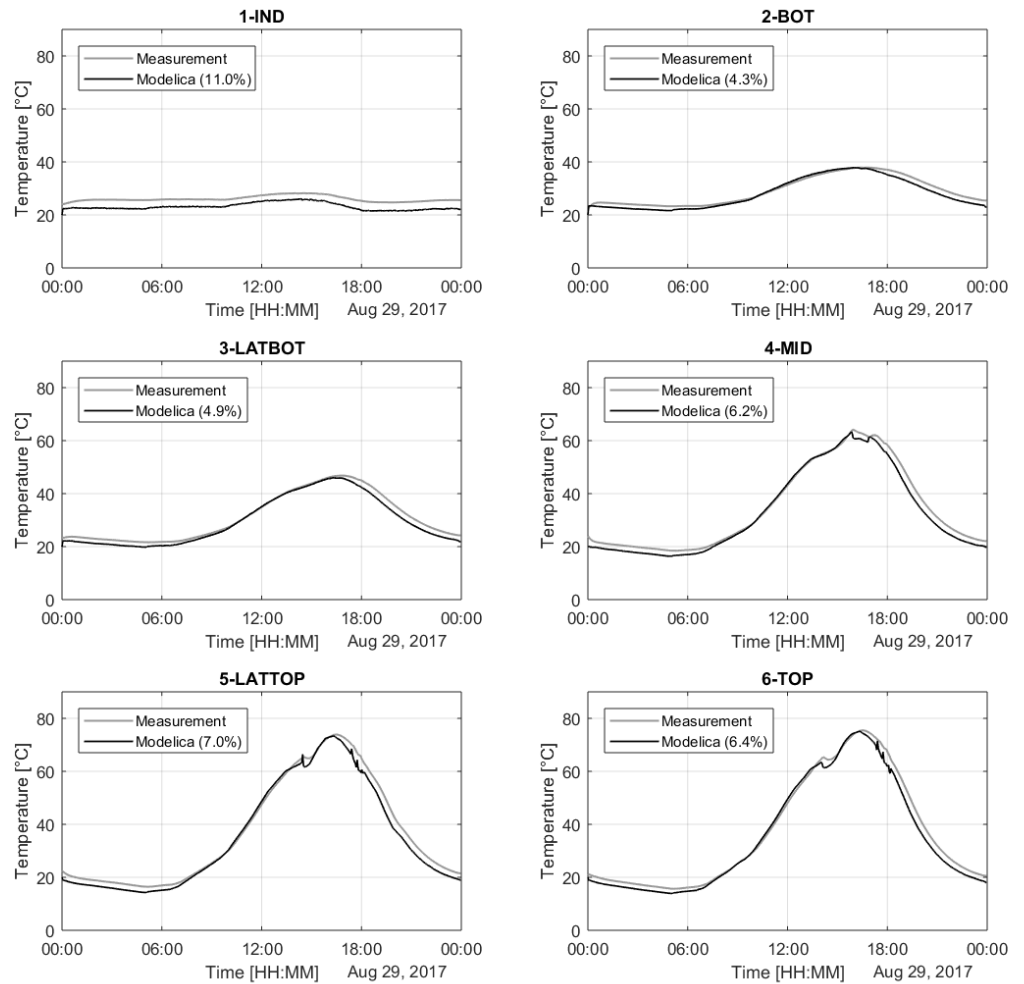

Figure A.18: Converter box temperature curves estimated with the proposed model (black) next to the experimental measurements (gray) for each placement scenario. Note, the model given in TRNSYS does not have the functionality to estimate the converter box temperature. 

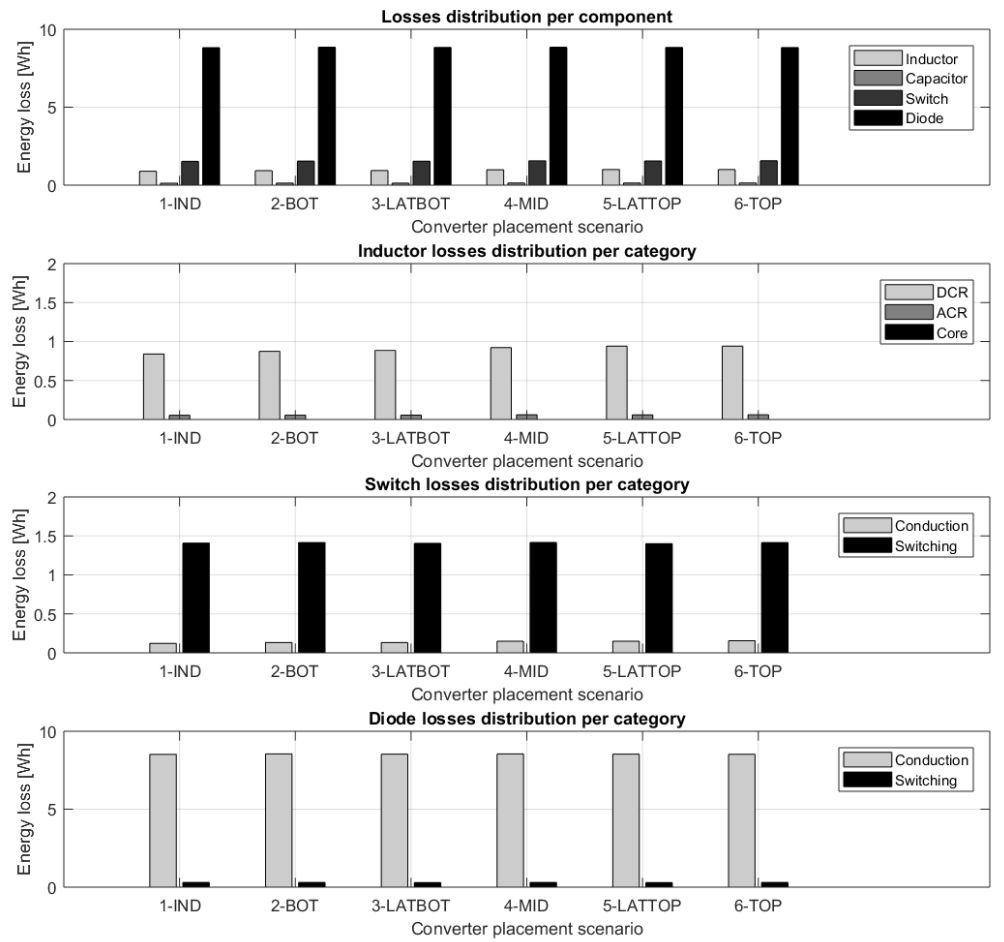

Figure A.19: Breakdown of the losses per component and per contributing factor. The breakdown is given for each of the scenarios presented in section 3 . 